NATIONAL LABORATORY

\title{
Application of Combined Sustained and Cyclic Loading Test Results to Alloy 617 Elevated Temperature Design Criteria
}

August 25, 2014

Prepared by

Yanli Wang, Robert I. Jetter and T.-L. Sham

Approved for public release.

Distribution is unlimited.

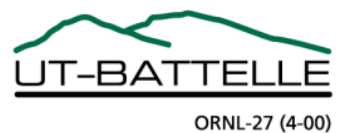




\section{DOCUMENT AVAILABILITY}

Reports produced after January 1, 1996, are generally available free via the U.S. Department of Energy (DOE) Information Bridge.

Web site http://www.osti.gov/bridge

Reports produced before January 1, 1996, may be purchased by members of the public from the following source.

National Technical Information Service

5285 Port Royal Road

Springfield, VA 22161

Telephone 703-605-6000 (1-800-553-6847)

TDD 703-487-4639

Fax 703-605-6900

E-mail info@ntis.gov

Web site http://www.ntis.gov/support/ordernowabout.htm

Reports are available to DOE employees, DOE contractors, Energy Technology Data Exchange (ETDE) representatives, and International Nuclear Information System (INIS) representatives from the following source.

Office of Scientific and Technical Information

P.O. Box 62

Oak Ridge, TN 37831

Telephone 865-576-8401

Fax 865-576-5728

E-mail reports@osti.gov

Web site http://www.osti.gov/contact.html

This report was prepared as an account of work sponsored by an agency of the United States Government. Neither the United States Government nor any agency thereof, nor any of their employees, makes any warranty, express or implied, or assumes any legal liability or responsibility for the accuracy, completeness, or usefulness of any information, apparatus, product, or process disclosed, or represents that its use would not infringe privately owned rights. Reference herein to any specific commercial product, process, or service by trade name, trademark, manufacturer, or otherwise, does not necessarily constitute or imply its endorsement, recommendation, or favoring by the United States Government or any agency thereof. The views and opinions of authors expressed herein do not necessarily state or reflect those of the United States Government or any agency thereof. 


\section{Application of Combined Sustained and Cyclic Loading Test Results to} Alloy 617 Elevated Temperature Design Criteria

Yanli Wang, Robert I. Jetter* and T.-L. Sham,

\footnotetext{
* Global Engineering and Technology, LLC
}

Date Published: August 25, 2014

Prepared under the direction of the

U.S. Department of Energy

Office of Nuclear Energy

Small Modular Reactors Research and Development (SMR R\&D) Program

Advanced SMR Research and Development Project

Prepared by

OAK RIDGE NATIONAL LABORATORY

Oak Ridge, Tennessee 37831-6283

managed by

UT-BATTELLE, LLC

for the

U.S. DEPARTMENT OF ENERGY

under contract DE-AC05-00OR22725 
Page Intentionally Blank 


\section{ACKNOWLEDGMENTS}

This research was sponsored by the U.S. Department of Energy, Office of Nuclear Energy, for the Small Modular Reactors (SMR) Research and Development Program. We gratefully acknowledge the support provided by Brian Robinson of DOE-NE, Advanced Reactor Technologies, SMR R\&D Program Manager; William Corwin of DOE-NE, Advanced Reactor Technologies, Materials Technology Lead; Robert Hill of Argonne National Laboratory, SMR R\&D National Technical Director; and Richard Wright of Idaho National Laboratory, Technical Area Lead, High Temperature Design Methodology.

The contribution of Charles S. Hawkins of the Oak Ridge National Laboratory (ORNL) in this testing program by setting up and running the experiments is greatly appreciated. David L. Thomas of ORNL configured the hardware for coupling two servo-hydraulic machines and Donald L. Erdman III of ORNL programmed the controls and established the initial experimental setup. Student interns, Svjetlana Stekovic and Seth Baird, have contributed to this report by collecting data and performing part of the data analysis. The time spent by James G. Hemrick, Edgar Lara-Curzio and Randy K. Nanstad of ORNL in reviewing this report is also greatly appreciated.

We would also like to acknowledge Richard N. Wright for supplying the Alloy 617 materials to support the testing task of this work. 
Page Intentionally Blank 


\section{EXECUTIVE SUMMARY}

Alloy 617 is a reference structural material for very high temperature components of advanced-gas cooled reactors with outlet temperatures in the range of $900-950^{\circ} \mathrm{C}$. In order for designers to be able to use Alloy 617 for these high temperature components, Alloy 617 has to be approved for use in Section III (the nuclear section) of the American Society of Mechanical Engineers (ASME) Boiler and Pressure Vessel Code. A plan has been developed to submit a draft code for Alloy 617 to ASME Section III by 2015. However, the current rules in Subsection NH for the evaluation of strain limits and creep-fatigue damage using simplified methods based on elastic analysis have been deemed inappropriate for Alloy 617 at temperatures above $1200^{\circ} \mathrm{F}\left(650^{\circ} \mathrm{C}\right)$. The rationale for this exclusion is that at higher temperatures it is not feasible to decouple plasticity and creep deformation, which is the basis for the current simplified rules. This temperature, $1200^{\circ} \mathrm{F}$, is well below the temperature range of interest for this material in High Temperature Gas Cooled Reactor (HTGR) applications. The only current alternative is, thus, a full inelastic analysis which requires sophisticated material models which have been formulated but not yet verified. To address this issue, proposed code rules have been developed which are based on the use of elastic-perfectly plastic (EPP) analysis methods and which are expected to be applicable to very high temperatures.

These two-bar tests discussed herein are part of an ongoing series of tests of Alloy 617 subjected to cyclic loading at high temperature range of $650^{\circ} \mathrm{C}$ to $950^{\circ} \mathrm{C}$ using specimens representing key features of potential component designs. The overall focus of the two-bar ratcheting test program is to verify the procedure for evaluation of strain limits at very high temperatures.

In the two-bar test methodology, the two bars can be viewed as specimens taken out of a tubular component across the wall thickness representing the inner wall element and the outer wall element respectively. The two bars are alternately heated and cooled under sustained axial loading to generate ratcheting. A sustained hold time is introduced at the hot extreme of the cycle to capture the accelerated ratcheting and strain accumulation due to creep. Since the boundary conditions are a combination of strain control and load control it is necessary to use two coupled servo-controlled testing machines to achieve the key features of the two-bar representation of actual component behavior.

Two-bar thermal ratcheting test results with combinations of applied mean stresses, transient temperature difference and heating and cooling rates were recorded. Tests performed at heating and cooling rates of $30^{\circ} \mathrm{C} / \mathrm{min}$ are comparable to a strain rate of $10^{-5} / \mathrm{sec}$. At high mean stresses in tension the direction of ratcheting was in-phase with the load, e.g. tensile strain ratcheting under high tensile loading; however, at lower loads, strain ratcheting in compression was observed under net tensile mean stresses. The strain accumulation was proportional to the applied thermal load. However, there was a narrow range of applied load in which the high applied thermal loading did not result in significant strain accumulation. These results are being used to assess the applicability of the proposed design rules for strain limits in the creep regime, particularly at high temperature range of $650^{\circ} \mathrm{C}$ to $950^{\circ} \mathrm{C}$ for Alloy 617 . 
Page Intentionally Blank 


\section{CONTENTS}

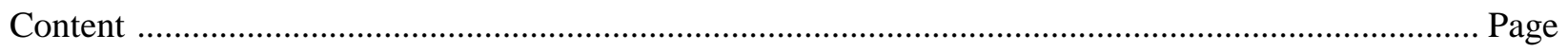

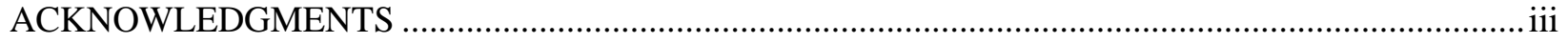

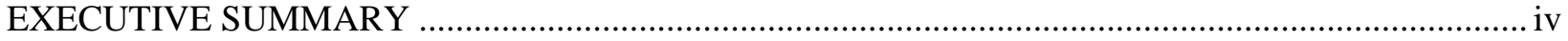

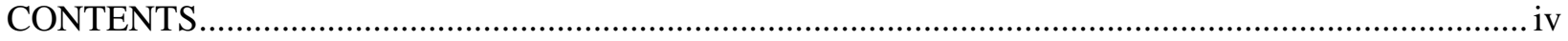

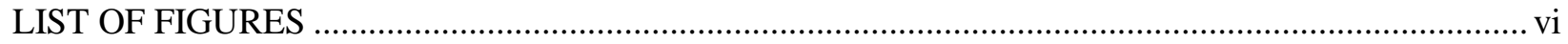

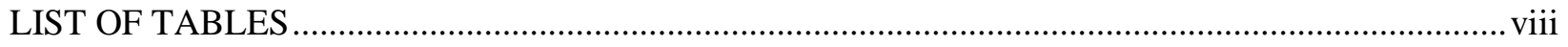

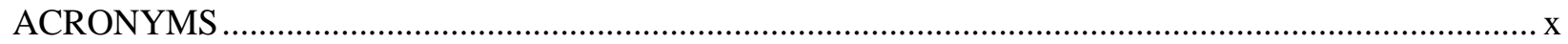

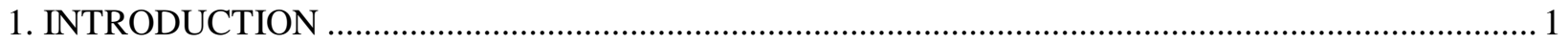

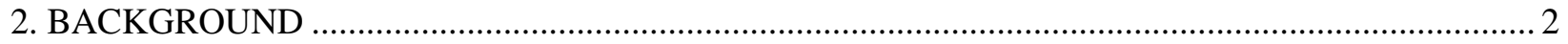

3. TWO-BAR THERMAL RATCHETING EXPERIMENTS ....................................................... 3

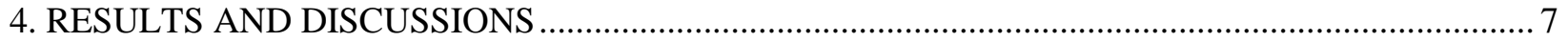

4.1 Long Term Two-Bar Thermal Ratcheting Test ................................................... 7

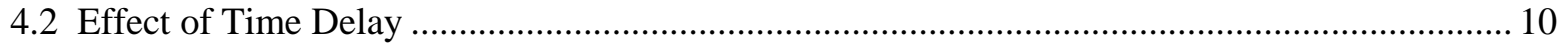

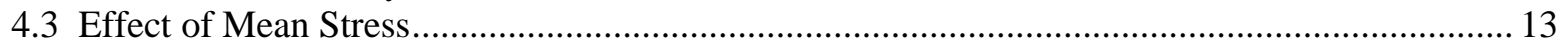

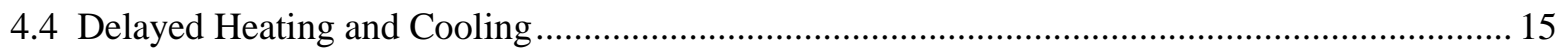

4.5 Effect of Heating and Cooling Rates .......................................................................... 17

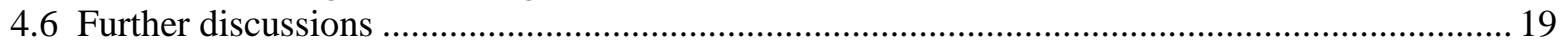

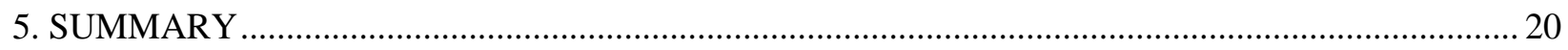

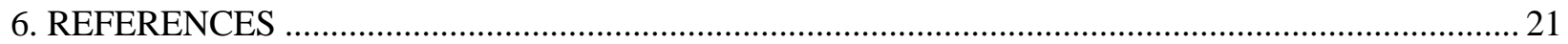


Intentionally Blank 


\section{LIST OF FIGURES}

Figure

Fig. 1. Pressurized cylinder with radial thermal gradient (a) and the equivalent two-bar model (b).......... 4

Fig. 2. Experimental setup with the igniter heater ................................................................................ 4

Fig. 3. Specimen geometry of Alloy 617 used in two-bar thermal ratcheting experiments. Units

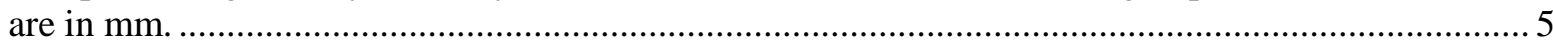

Fig. 4. Temperature vs. time histogram for two-bar thermal ratcheting experiments on Alloy $617 \ldots \ldots \ldots \ldots . . .6$

Fig. 5. Temperature (A), stress (B), total strain (C) and mechanical strain (D) versus time profiles

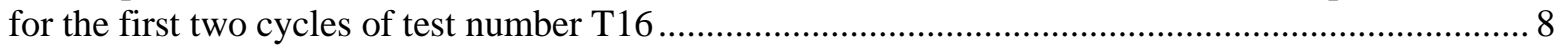

Fig. 6. Maximum and minimum total strains for test number T16 ............................................... 9

Fig. 7. Maximum and minimum stresses for test number T16 ......................................................... 9

Fig. 8. Stress vs Mechanical strain plots of the first three cycles for Bar 1 (a) and Bar 2 (b) for test number T16

Fig. 9. Effect of time delay on the maximum and minimum total strains and stresses at a mean

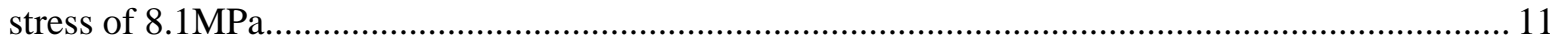

Fig. 10. Effect of time delay on the ratcheting strains at a mean stress of $8.1 \mathrm{MPa}$.............................. 11

Fig. 11 Stress vs. mechanical strain plots for Bar 1 and Bar 2 for test numbers T17-1 (a, b), T17-2

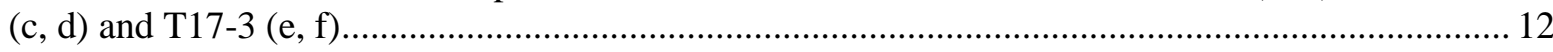

Fig. 12. Effect of applied mean stresses on the maximum and minimum total strains and stresses

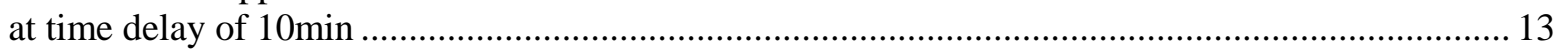

Fig. 13. Effect of applied mean stresses on the ratcheting strains at time delay of 10min ..................... 14

Fig. 14. Stress vs. mechanical strain plots for Bar 1 and Bar 2 for test numbers T17-7 (a, b), T18-5

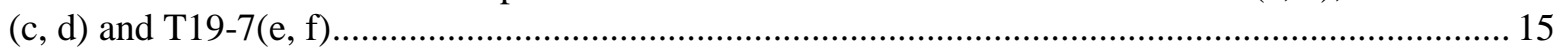

Fig. 15. Comparison of effect of delayed cooling and delayed heating ............................................... 16

Fig. 16. Stress vs. mechanical strain plots for Bar 1 and Bar 2 for test numbers T17-7 (a, b) and

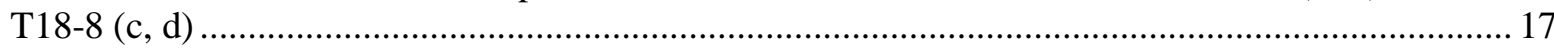

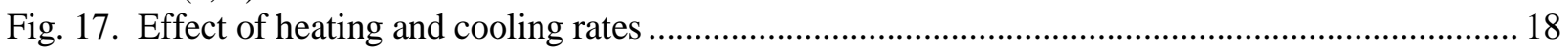

Fig. 18. Stress vs. mechanical strain plots for Bar 1 and Bar 2 for test numbers T17-7 (a, b) and T18-8 (c, d) . 
Intentionally Blank 


\section{LIST OF TABLES}

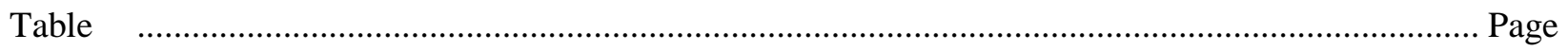

Table 1. Chemical compositions of Alloy 617 plate with heat number 314626 (weight \%) .....................5

Table 2. Summary of two-bar thermal ratcheting experiments on Alloy 617.......................................... 7 
Intentionally Blank 


\section{ACRONYMS}

ASME

ANL

CRBR

DOE

EPP

HTGR

IHX

INL

LMFBR

ORNL

SMR

VHTR
American Society of Mechanical Engineers

Argonne National Laboratory

Clinch River Breeder Reactor

Department of Energy

Elastic-Perfectly Plastic

High Temperature Gas-cooled Reactor

Intermediate Heat Exchanger

Idaho National Laboratory

Liquid Metal-Cooled Fast Breeder Reactor

Oak Ridge National Laboratory

Small Module Reactor

Very High Temperature Reactor 
Intentionally Blank 


\section{INTRODUCTION}

Alloy 617 is a reference structural material for very high temperature components of advanced-gas cooled reactors with outlet temperatures in the range of $900-950^{\circ} \mathrm{C}$. In order for designers to be able to use Alloy 617 for these high temperature components, Alloy 617 has to be approved for use in Section III (the nuclear section) of the American Society of Mechanical Engineers (ASME) Boiler and Pressure Vessel Code. A plan has been developed to submit a draft code for Alloy 617 to ASME Section III by 2015. There has not been a new high temperature material approved for use in Section III for almost 20 years. The Alloy 617 Code Case effort would also lead the way to establish a path for code qualification of new high temperature materials of interest for other advanced Small Module Reactors (SMR).

The current rules in Subsection NH for the evaluation of strain limits and creep-fatigue damage using simplified methods based on elastic analysis have been deemed inappropriate for Alloy 617 at temperatures above $1200^{\circ} F\left(650^{\circ} \mathrm{C}\right)$ (Corum and Blass, 1991). The rationale for this exclusion is that at higher temperatures it is not feasible to decouple plasticity and creep deformation, which is the basis for the current simplified rules. This temperature, $1200^{\circ} \mathrm{F}$, is well below the temperature range of interest for this material for the High Temperature Gas Cooled Reactor (HTGR). The only current alternative is, thus, a full inelastic analysis which requires sophisticated material models which have been formulated but not yet verified. An additional impediment to the use of full inelastic analysis is the level of expertise and experience required to implement these models and interpret the results.

To address this issue, proposed code rules have been developed which are based on the use of elasticperfectly plastic (EPP) analysis methods and which are expected to be applicable to very high temperatures with the range $900-950^{\circ} \mathrm{C}$. The proposed rules for strain limits and creep-fatigue evaluation were initially documented in the technical literature, Carter, et al., (2012a) and Carter, et al., (2012b), and have been recently revised to incorporate comments and simplify their application. These two-bar tests are part of an ongoing very high temperature series of tests of Alloy 617 subjected to cyclic loading using specimens representing key features of potential component designs.

The two-bar test concept was initiated to support high temperature design criteria for the Clinch River Breeder Reactor (CRBR). The goal of the two-bar test is to simulate the thermal ratcheting failure mode which is the basis of the strain limit design criteria in Subsection NH of Section III. This type of testing was originally performed on $2 \frac{1}{4} \mathrm{Cr}$-1Mo steel (Swindeman, et al., 1982) to support the verification of the recommended constitutive equations for liquid metal-cooled fast breeder reactor (LMFBR) applications. However, the current very high temperature two-bar test results on Alloy 617 will also, initially, be used to validate the newly proposed simplified methodology for assessment of strain limits at very high temperatures where the current NH methodology has been deemed inappropriate for Alloy 617.

In the two-bar test methodology, the two bars can be viewed as specimens taken out of a tubular component across the wall thickness representing the inner wall element and the outer wall element. The two bars are alternately heated and cooled under sustained axial loading to generate ratcheting. A sustained hold time is introduced at the hot extreme of the cycle to capture the accelerated ratcheting and strain accumulation due to creep. Since the boundary conditions are a combination of strain control and load control it is necessary to use two coupled servo-controlled testing machines to achieve the key features of the two-bar representation of actual component behavior.

The preceding work on the two-bar test program by Wang et. al. (2013) was focused on establishing the two-bar thermal ratcheting test procedure for Alloy 617 and the evaluation of the material ratcheting behavior at relatively slow imposed heating and cooling thermal transient rates of $5^{\circ} \mathrm{C} / \mathrm{min}$. These rates 
were compatible with heating and cooling rates achievable with existing heaters and measurement and control system characteristics. However, there was an incentive to test at implied strain rates compatible with creep-fatigue tests that have been conducted for Alloy 617 by Carrol et al. $(2010,2013)$ in support of its codification in Section III of the ASME Boiler and Pressure Vessel Code. Although most of the creepfatigue tests were performed at a strain rate of $10^{-3} / \mathrm{sec}$ in those test programs, there are data available at a strain rate of $10^{-5} / \mathrm{sec}$ that are comparable to the $30^{\circ} \mathrm{C} / \mathrm{min}$ thermal transient rates employed in this phase of the Two-bar test program. Accordingly, modifications were made which enabled testing at $30^{\circ} \mathrm{C} / \mathrm{min}$. In addition, in assessing the test results from preceding work of the thermal ratcheting study on Alloy 617, testing parameters were refined and focused on the conditions that were most relevant to the development of design rules for strain limits at very high temperatures.

\section{BACKGROUND}

The current high temperature design rules in Subsection NH consider two basic categories of load application. The first is called load controlled and represents the stresses that are in equilibrium with externally applied loads and moments. A basic example is the stress in the wall of a pressure vessel due to an internal pressure, remote from structural discontinuities. These stresses generally dictate required wall thickness. The second basic category is identified as displacement controlled. In this category are stress levels generated at local structural discontinuities and by restrained thermal expansion. An example would be the thermal stress in the wall of a vessel due to a radial thermal gradient. The basic characteristic of these stresses is that, when combined with load controlled stresses, they limit the number of cycles that a component can withstand without cracking or distortion. Displacement controlled stress limits are based on limiting the amount of strain that can accumulate and the number of cyclic loadings that can be applied without cracking. The former are called strain limits and the latter, creep-fatigue damage. Separate design criteria are used to evaluate strain limits and creep-fatigue and the focus of the two-bar ratcheting test program is verification of the procedure for evaluation of strain limits at very high temperatures.

Although creep-fatigue damage accumulation is often the critical failure mode for elevated temperature structures, strain limits are frequently design limiting and, additionally, satisfaction of the strain limits criteria is prerequisite to consideration of creep-fatigue limits in the current rules in Subsection NH.

However, there is a problem with the current rules for strain limits. Two methods are currently provided. One is based on a complete modeling of the response of the structure throughout the life of the component to generate stress and strain histories from which the accumulated strain and creep-fatigue damage can be ascertained. Although conceptually straightforward, there are many practical difficulties in this approach; one of the most critical is that it is necessary to correctly account in full detail for all of the material behaviors over a wide range of temperatures and loading histories and go through a process of validating these complex constitutive models. The other method is to rely on mechanistic models based on the results of elastic analysis to bound the true inelastic response of the structure. These are usually referred to as simplified methods, although they can be quite complex in practice, because they are based on the much simpler assumed elastic material model.

The current simplified methods for evaluation of strain limits are based on the potential incremental distortion or ratcheting that occurs in a pressurized cylinder when subjected to cyclic through wall thermal gradients. This model development is attributed to Bree (1967) and was extended by O'Donnell and Porowsky (1991) to recognize that the strain in the cylinder could be bounded by the elastically calculated core stress in the wall provided that it was less than yield. This concept was further extended by Sartory (1989) to handle non-linear thermal gradients and strain concentrations. However, the common 
feature of all these methods is that they are based on the concept that inelastic strains due to time dependent creep can be accounted for separately from time independent plastic strain. In fact, the elastically calculated parameters in these methods are implementable for a variety of materials because they are normalized by the yield strength. However, at very high temperatures time dependent creep and time independent plasticity are indistinguishable and there is not a uniform yield strength at a given temperature but in effect, a series of effective yield strengths that are strain rate and stress history dependent. It is for these reasons that the current simplified methods in Subsection NH were deemed inappropriate for Alloy 617 at temperatures above $1200^{\circ} \mathrm{F}\left(650^{\circ} \mathrm{C}\right)$.

To address this dilemma, and to provide a simpler, more effective approach to evaluation of strain limits, a cyclic elastic-perfectly plastic analysis method has been proposed which provides a conservative estimate of cyclic creep strain accumulation within the ratchet boundary. The method is to check for ratcheting based on an elastic-perfectly plastic material model with a temperature-dependent pseudo yield stress defined by temperature, time and stress to give $1 \%$ accumulated inelastic strain. It does not require stress classification and is also applicable to a full range of temperatures above and below the creep regime. The development and justification of this methodology is documented in Carter et al. (2012).

Since the "yield strength" used in the analysis is not an actual yield strength but, rather, a pseudo yield strength that represents the time and stress to give 1\% accumulated inelastic strain; it avoids the issue of strain rate dependent yield strength and the lack of distinction between plasticity and creep at very high temperatures. The use of this methodology is part of the plan to gain approval of a code case for the use of Alloy 617 at temperatures up to and including $950^{\circ} \mathrm{C}$ for Class I (or Class A in Section III, Division 5 terminology) components. The primary purpose of the two-bar test program is to provide experimental data to verify the proposed new rules. However, this data can also be used to develop, refine and validate the elevated temperature constitutive material models which would be used to perform full inelastic analysis if the simplified method were too conservative for a particular component design configuration and operating conditions.

\section{TWO-BAR THERMAL RATCHETING EXPERIMENTS}

The test procedure of two-bar thermal ratcheting for Alloy 617 was developed and presented in detail in the preceding report by Wang et al. $(2013,2014)$. As schematically shown in Fig. 1, the two bars can be viewed as specimens taken out of a tubular component across the wall thickness representing the inner and outer wall elements. The through wall temperature gradient, $\Delta T$, is represented by the temperature difference between the bars. The sustained pressure load, $F$, is generated by the internal pressure, $P$, and it is represented by total load on the two bars. The combined thermal transients and sustained pressure load can generate a ratchet (progressive deformation) mechanism.

The control logic used is similar to what was reported by Swindeman et al. (1982). In this method, two coupled servo-controlled machines are used to implement two bars in a parallel testing condition and the control system forces equal strains in the two specimens, yet allows the applied total load to be constant. The testing concept for two bars in parallel was demonstrated for various mean stresses and thermal histories for Alloy 617 by Wang et al. (2013, 2014), among which, the low mean stress conditions were identified to be most interesting for verification of the Elastic Perfect-Plastic (EPP) methodology for strain limits design criteria. 


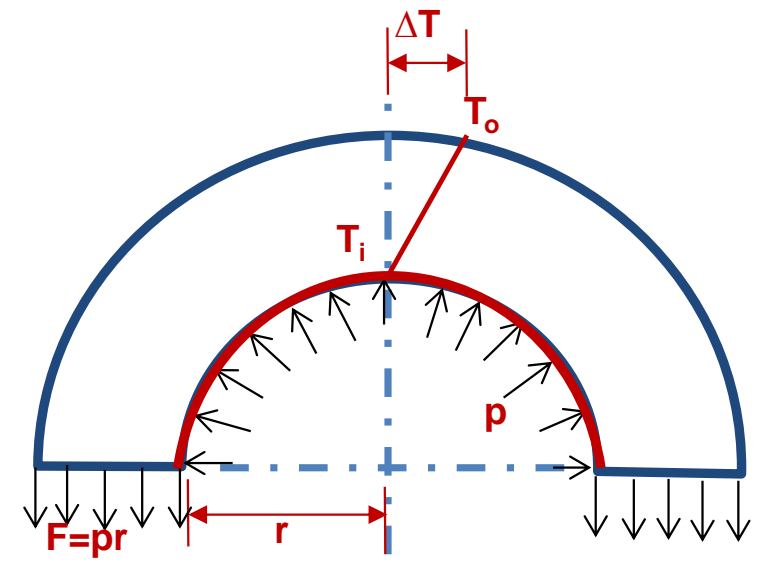

(a)

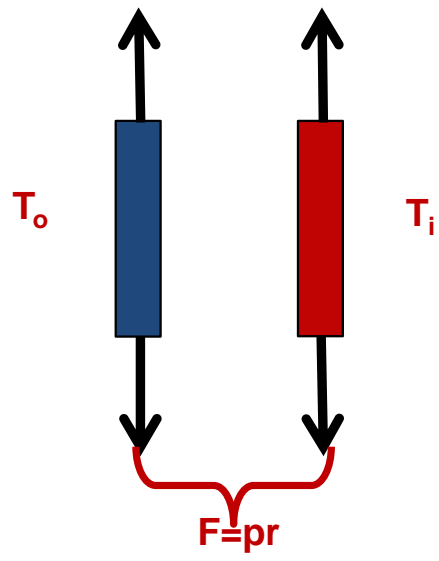

(b)

Fig. 1. Pressurized cylinder with radial thermal gradient (a) and the equivalent two-bar model (b)

In this study, the heating systems were replaced with heaters made of igniter heating elements that are capable of faster heating and cooling rates of $30^{\circ} \mathrm{C} / \mathrm{min}$ as compared to the previous tests performed at $5^{\circ} \mathrm{C} / \mathrm{min}$. A picture of the experimental setup for one of the bars is shown in Fig. 2. The top and bottom tabs of the specimen are attached with heating coils to achieve three-zone temperature control. The thermal loading cycles are controlled and automated by LabView software. The temperature difference within the gage length of the specimen was less than $1 \%$ of the target temperature. Additionally, the thermal expansions measured by the extensometers were compared to make sure there was no slippage or false readings during testing.

Due to much more compact design of the new heaters, the total length of the specimen was reduced to $177.8 \mathrm{~mm}$ (7in). The test specimens were manufactured from the same Alloy 617 plate, Heat 314626 from ThyssenKrupp VDM USA, Inc., with the longitudinal direction parallel to the rolling direction of the plate, similar to the preceding work by Wang et al. (2013). Chemical compositions of the plate are shown in Table 1. The gage section of the test specimens is the same as the preceding work; with a gage length of $19.05 \mathrm{~mm}(0.75 \mathrm{in})$ and diameter of $6.35 \mathrm{~mm}(0.25 \mathrm{in})$. A drawing of the specimen geometry is shown in Fig. 3.

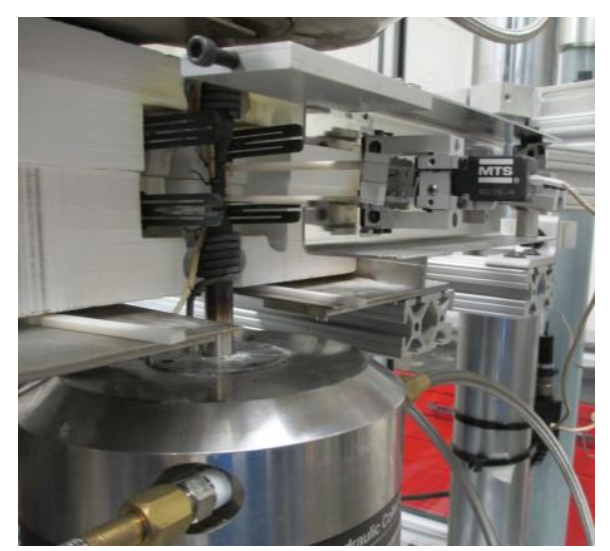

Fig. 2. Experimental setup with the igniter heater 
Table 1. Chemical compositions of Alloy 617 plate with heat number 314626 (weight \%)

\begin{tabular}{c|c|c|c|c|c|c|c|c|c|l|l|c}
\hline $\mathbf{C}$ & $\mathbf{S}$ & $\mathbf{C r}$ & $\mathbf{N i}$ & $\mathbf{M n}$ & $\mathbf{S i}$ & $\mathbf{M o}$ & $\mathbf{T i}$ & $\mathbf{C u}$ & $\mathbf{F e}$ & $\mathbf{A l}$ & $\mathbf{C o}$ & $\mathbf{B}$ \\
\hline 0.05 & $<0.002$ & 22.2 & $\mathrm{R} 54.1$ & 0.1 & 0.1 & 8.6 & 0.4 & 0.04 & 1.6 & 1.1 & 11.6 & $<0.001$ \\
\hline
\end{tabular}

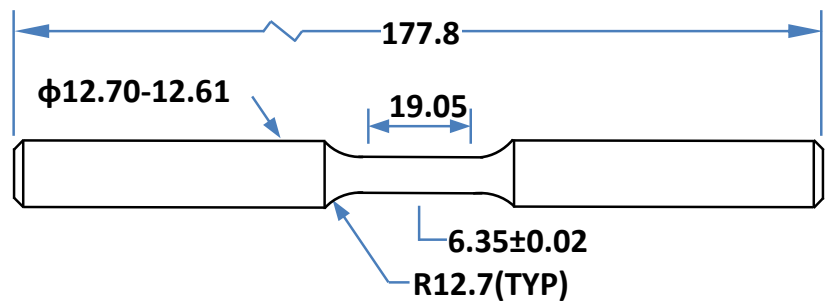

Fig. 3. Specimen geometry of Alloy 617 used in two-bar thermal ratcheting experiments. Units are in mm.

Fig. 4 shows the two types of temperature versus time profiles used in this study with Fig. 4A showing the case with a time delay between the two bars on the cooling segment and Fig. 4B with a time delay on the heating segment. Results from 10 tests are presented and the testing parameters of these tests are listed in Table 1. Results from 10 tests are presented and the testing parameters of these tests are listed in Table 1. All experiments performed in this study used a temperature range of $650^{\circ} \mathrm{C}$ to $950^{\circ} \mathrm{C}$. The common hold time of the two bars at $950^{\circ} \mathrm{C}$ was $1 \mathrm{hr}$. The preceding work used different testing temperature ranges to create different levels of thermal stresses, instead, the same temperature range of $650^{\circ} \mathrm{C}$ to $950^{\circ} \mathrm{C}$ was used and the time delay between the two bars was varied to create different levels of thermal stresses in this study. The consistent temperature range for all testing conditions enables the application of the same temperature dependent material models in the theoretical analysis. The heating and cooling rates were $30^{\circ} \mathrm{C} / \mathrm{min}$ except for test number T18-9, in which slow heating and cooling rates of $5^{\circ} \mathrm{C} / \mathrm{min}$ were used. The purpose for different levels of heating and cooling rates was to evaluate the strain rate effects on the ratcheting behavior of Alloy 617 under the two-bar in parallel test condition. Low mean stress levels were selected and the variations of the applied mean stress are also listed in Table 2. Test number T16 and T17-1 used new specimens. Sequential tests T17-1, T17-2 and T17-3 along with T17-7 were tested on the same sets of specimens; and T18-5, T18-6, T18-7, T18-8 and T18-9 were also tested sequentially on the same sets of specimens. The changing of the test parameters was performed at $650^{\circ} \mathrm{C}$, i.e., after the last cycle of the previous test condition. There were residual stresses and strains in the two bars when sequential tests were performed, and the values of the stresses and the strains prior to the testing condition are listed in Table 2

Consistent with our proceeding work by Wang et al. $(2013,2014)$, the ratcheting strain is defined as the difference in the mechanical strain at a time point in a cycle and that at the same time point in the reference cycle. The mechanical strain is the sum of the elastic strain and inelastic strain, and it can be extracted from the test data by subtracting the thermal expansion from the total strain. When the same reference point in the thermal cycle is selected, the amount of ratcheting strain calculated based on the total strain is the same as that calculated based on mechanical strain. In this study, the ratcheting strains were calculated from the maximum total strains of each cycle, and they were approximately the same values when calculated based on the minimum strains. It was observed that the cyclic ratcheting rates were approximately constant and the shape of the hysteresis loops were uniform for all the tests conducted. Thus, results from shorter test periods were extrapolated to obtain the ratcheting strain at $200 \mathrm{hr}$ to provide information to our parallel theoretical studies on strain limits of Alloy 617. 

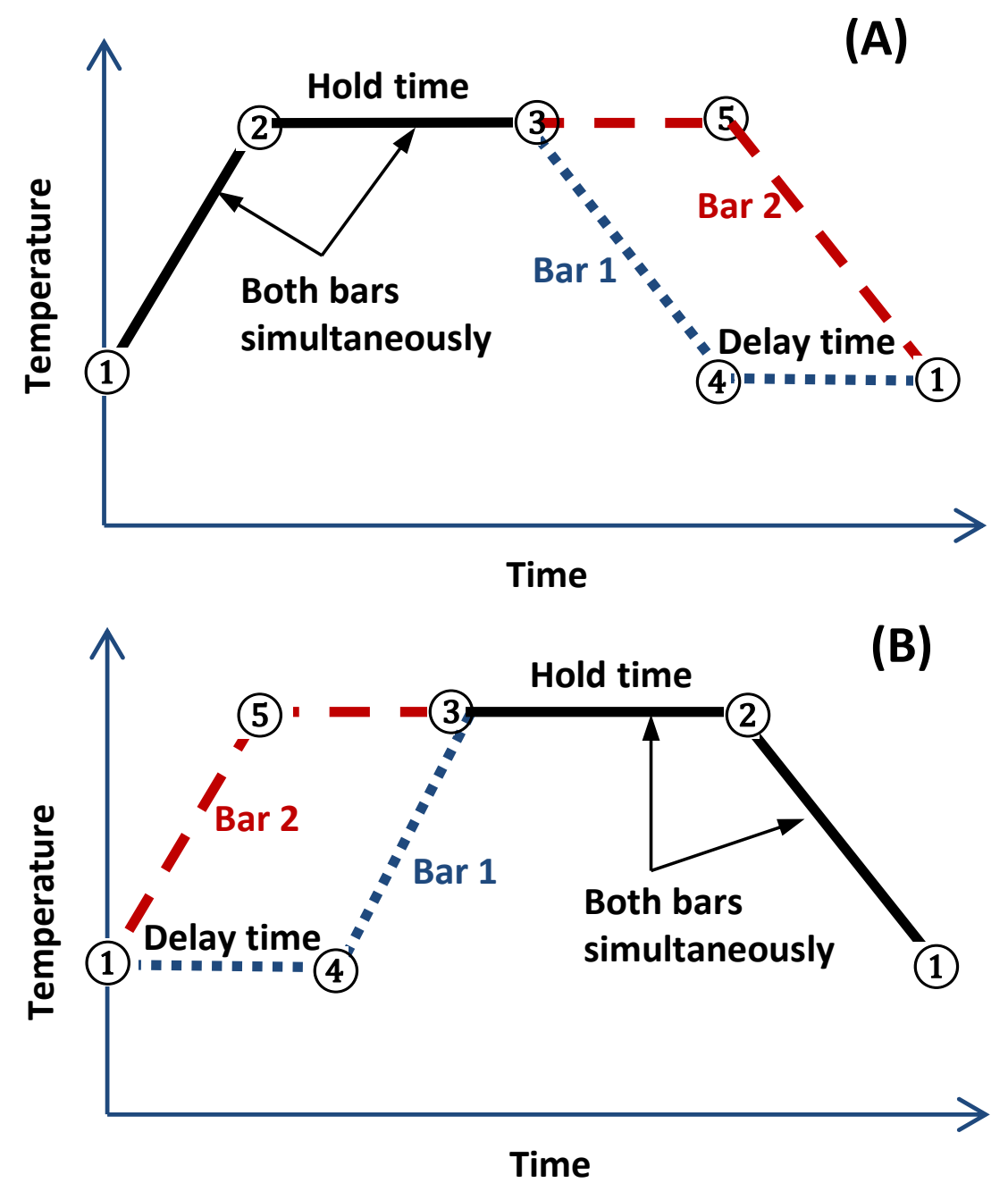

Fig. 4. Temperature vs. time histogram for two-bar thermal ratcheting experiments on Alloy 617

Our past experience shows that the transitioning cycle from one testing condition to another is significantly different and therefore is ignored in the ratcheting strain extrapolations. For comparison purposes, the first cycles of T16 and T17-1 and the second cycles of the rest of the testing conditions were selected as the reference cycles. The maximum and minimum strains of each testing condition were offset by the minimum strains of their reference cycles and summarized on corresponding plots in order to make direct comparisons between different conditions in the following discussions. The minimum strains of the reference cycles for these 10 testing conditions are listed in Table 2 . 
Table 2. Summary of two-bar thermal ratcheting experiments on Alloy 617

\begin{tabular}{|c|c|c|c|c|c|c|c|c|c|c|}
\hline Test No. & T16 & $T 17-1$ & $T 17-2$ & $T 17-3$ & $T 17-7$ & $T 18-5$ & T18-6 & $T 18-7$ & $T 18-8$ & T18-9 \\
\hline $\begin{array}{l}\text { Applied mean } \\
\text { stress, } \mathrm{MPa}\end{array}$ & $\begin{array}{l}8.1 \\
\pm 1.5\end{array}$ & $\begin{array}{l}8.1 \\
\pm 1.5\end{array}$ & $\begin{array}{l}7.8 \\
\pm 1.5\end{array}$ & $\begin{array}{l}7.8 \\
\pm 1.5\end{array}$ & $\begin{array}{l}4.2 \\
\pm 1.5\end{array}$ & $\begin{array}{l}15.5 \\
\pm 1.8\end{array}$ & $\begin{array}{l}19.5 \\
\pm 1.5\end{array}$ & $\begin{array}{l}23.0 \\
\pm 1.5\end{array}$ & $\begin{array}{l}4.2 \\
\pm 1.5\end{array}$ & $\begin{array}{l}4.6 \\
\pm 1.5\end{array}$ \\
\hline Time delay, min & 1 & 10 & 5 & 3 & 10 & 10 & 1 & 2 & 10 & 60 \\
\hline $\begin{array}{l}\text { Total No. of } \\
\text { cycles tested }\end{array}$ & 138 & 15 & 17 & 34 & 24 & 15 & 16 & 15 & 29 & 18 \\
\hline $\begin{array}{l}\text { Thermal profile } \\
\text { in Fig. } 4\end{array}$ & A & A & A & A & $\bar{A}$ & A & A & A & B & A \\
\hline $\begin{array}{l}\text { Ratcheting rate } \\
\text { (per cycle), \% }\end{array}$ & 0.005 & -0.067 & -0.008 & 0.00001 & $\begin{array}{l}- \\
0.099\end{array}$ & -0.01 & 0.004 & 0.017 & -0.015 & -0.08 \\
\hline $\begin{array}{l}\text { Initial stress on } \\
\text { Bar } 1, \mathrm{MPa}\end{array}$ & 8.2 & 6,9 & -212.1 & -183.5 & $-\overline{180.5}$ & 210.3 & -140 & -111.6 & -188.1 & -20.8 \\
\hline $\begin{array}{l}\text { Initial stress on } \\
\text { Bar 2, MPa }\end{array}$ & 9.1 & 8.4 & 224.8 & 197.7 & 190.6 & -177 & 178 & 156.6 & 195.8 & 28.6 \\
\hline $\begin{array}{l}\text { Initial residual } \\
\text { total strain, \% }\end{array}$ & 0 & 0 & -1.6 & -1.18 & -0.96 & -0.29 & -0.45 & -0.36 & -0.12 & -0.5 \\
\hline $\begin{array}{l}\text { Reference cycle } \\
\text { No. }\end{array}$ & 1 & 1 & 2 & 2 & 2 & 2 & 2 & 2 & 2 & 2 \\
\hline $\begin{array}{l}\text { Min. strain of } \\
\text { the reference } \\
\text { cycle, } \%\end{array}$ & -0.0017 & -0.14 & -0.48 & -1.14 & -1.29 & -0.33 & -0.43 & -0.33 & -0.91 & -0.8 \\
\hline $\begin{array}{l}\text { Stress range per } \\
\text { cycle for Bar } 1 \text {, } \\
\text { MPa }\end{array}$ & $\begin{array}{l}70.7 \\
\pm 1.3\end{array}$ & $\begin{array}{l}310.8 \\
\pm 3.1\end{array}$ & $\begin{array}{l}268.5 \\
\pm 1.7\end{array}$ & $\begin{array}{l}184.2 \\
\pm 2.5\end{array}$ & $\begin{array}{l}306.4 \\
\pm 5.1\end{array}$ & $\begin{array}{l}300 \\
\pm 2.8\end{array}$ & $\begin{array}{l}299.8 \\
\pm 3.0\end{array}$ & $\begin{array}{l}302.4 \\
\pm 2.4\end{array}$ & $\begin{array}{l}239.0 \\
\pm 1.1\end{array}$ & $\begin{array}{l}284.8 \\
\pm 5.5\end{array}$ \\
\hline $\begin{array}{l}\text { Stress range per } \\
\text { cycle for Bar } 1 \text {, } \\
\mathrm{MPa}\end{array}$ & $\begin{array}{l}67.3 \\
\pm 1.2\end{array}$ & $\begin{array}{l}305.9 \\
\pm 2.5\end{array}$ & $\begin{array}{l}264.8 \\
\pm 1.5\end{array}$ & $\begin{array}{l}180.6 \\
\pm 2.6\end{array}$ & $\begin{array}{l}301.5 \\
\pm 5.6\end{array}$ & $\begin{array}{l}297.7 \\
\pm 2.5\end{array}$ & $\begin{array}{l}297.4 \\
\pm 2.8\end{array}$ & $\begin{array}{l}300.7 \\
\pm 2.4\end{array}$ & $\begin{array}{l}236.7 \\
\pm 0.9\end{array}$ & $\begin{array}{l}283.3 \\
\pm 5.6\end{array}$ \\
\hline
\end{tabular}

\section{RESULTS AND DISCUSSIONS}

\subsection{LONG TERM TWO-BAR THERMAL RATCHETING TEST}

A long term two-bar thermal ratcheting test was performed on Alloy 617 to assess the material response to long term cyclic thermal loading under two-bar testing condition and the performance of the current two-bar testing system. The test number was T16 and the applied mean stress was $8.1 \pm 1.5 \mathrm{MPa}$ with a time delay of $1 \mathrm{~min}$ between the two bars. Fig. 5 presents the temperature, stress, total strain, and mechanical strain as a function of time for the first two cycles. At the beginning of the heating and initial holding segments, (1) $\rightarrow$ (2) $\rightarrow$ (3) (refer to Fig. 4A), the stresses on the two bars slightly deviated from 8.1 MPa. This deviation is due to the fact that the two systems are not identical, for example, the temperatures on the two bars were slightly different during the heating segment. The total strain increased from (1) $\rightarrow$ (2), due to the thermal expansion and inelastic deformation. Upon reaching $950^{\circ} \mathrm{C}$, the two bars did not equilibrate at the applied mean stress within the $1 \mathrm{hr}$ holding time of (2) $\rightarrow(3)$. The mechanical strains for both bars for these two segments were the same. During the cooling segment (3) $\rightarrow$ (4), the stress in Bar 1 increased in the tensile direction while the stress in Bar 2 increased in the compression direction. The changes in the stresses slowed down in both bars when Bar 2 started to cool. Bar 1 reached its maximum tensile stress and Bar 2 reached its maximum compressive stress when Bar 1 was cooled down to $650^{\circ} \mathrm{C}$ and $\mathrm{Bar} 2$ was at $680^{\circ} \mathrm{C}$. The stresses built in the two bars were released quickly and reached the mean stress level when Bar 2 also reached to $650^{\circ} \mathrm{C}$. The total strains in both bars were decreasing during this segment. 


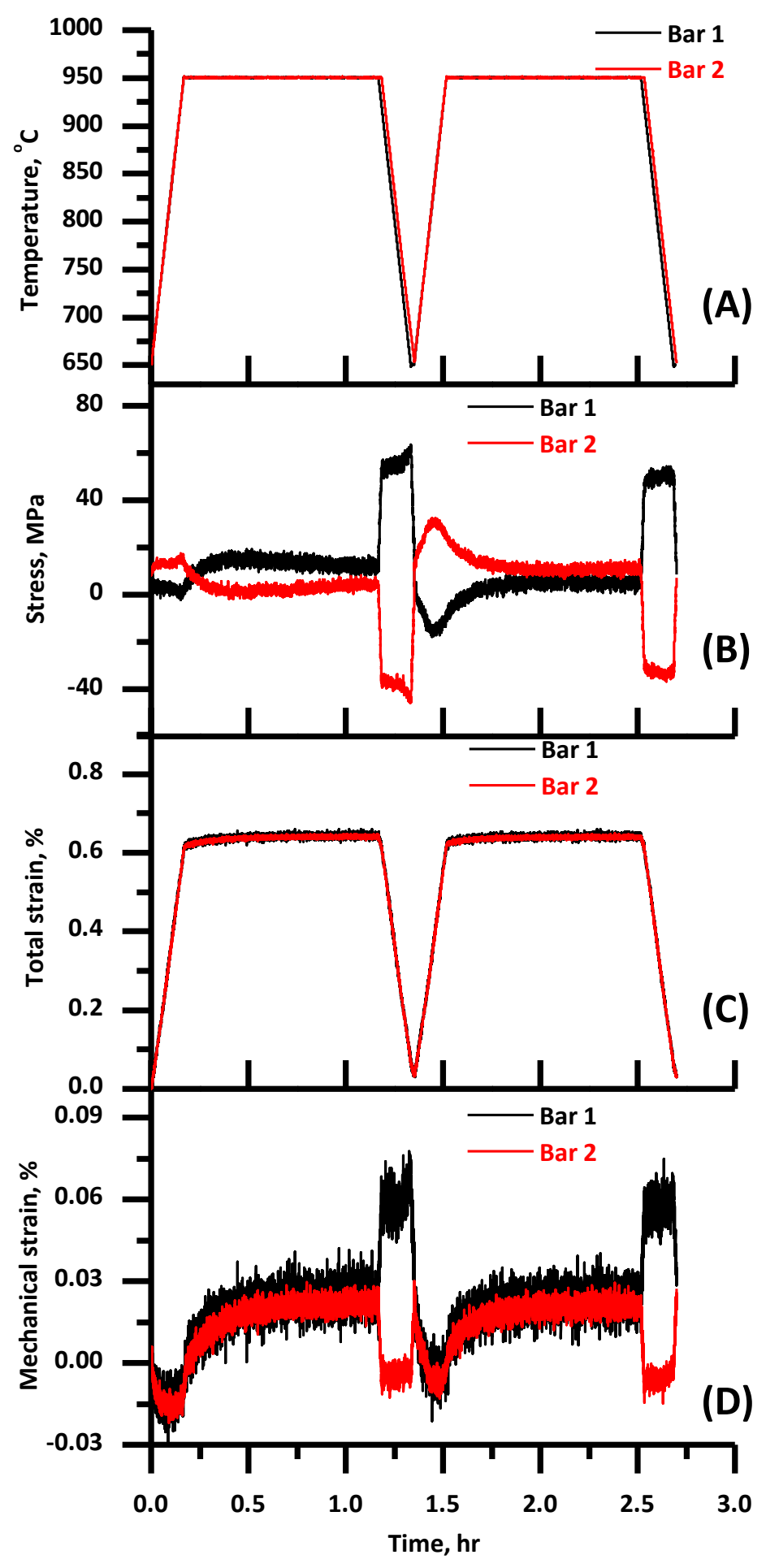

Fig. 5. Temperature (A), stress (B), total strain (C) and mechanical strain (D) versus time profiles for the first two cycles of test number T16

The test continued for 138 cycles, i.e., $186.3 \mathrm{hr}$, before the heater for Bar 1 failed. The maximum and minimum total strains of each thermal cycle are plotted in Fig. 6, and the ratcheting rate is relatively steady after the first cycle. The ratcheting strains were extrapolated for longer term, and the two bars 
ratchet $0.07 \%$ in $200 \mathrm{hr}$ under this test condition. The maximum and minimum stresses of each thermal cycle are summarized in Fig. 7. After the initial changes in about 5 cycles, the maximum and minimum stresses reached steady state for both bars. The maximum stresses were $56.4 \pm 1.1 \mathrm{MPa}$ and $29.2 \pm 1.2 \mathrm{MPa}$, and the minimum stresses were $-14.3 \pm 1.3 \mathrm{MPa}$ and $-38.1 \pm 1.0 \mathrm{MPa}$ for Bar 1 and Bar 2, respectively. The average stress ranges of the tested cycles are summarized in Table 2. The stress range of Bar 1 was slightly larger than Bar 2.

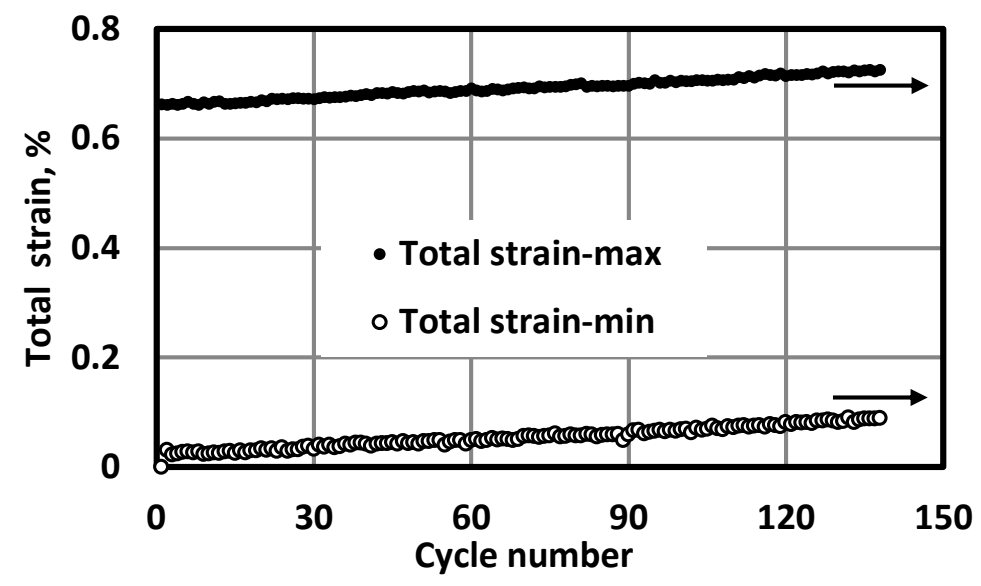

Fig. 6. Maximum and minimum total strains for test number T16

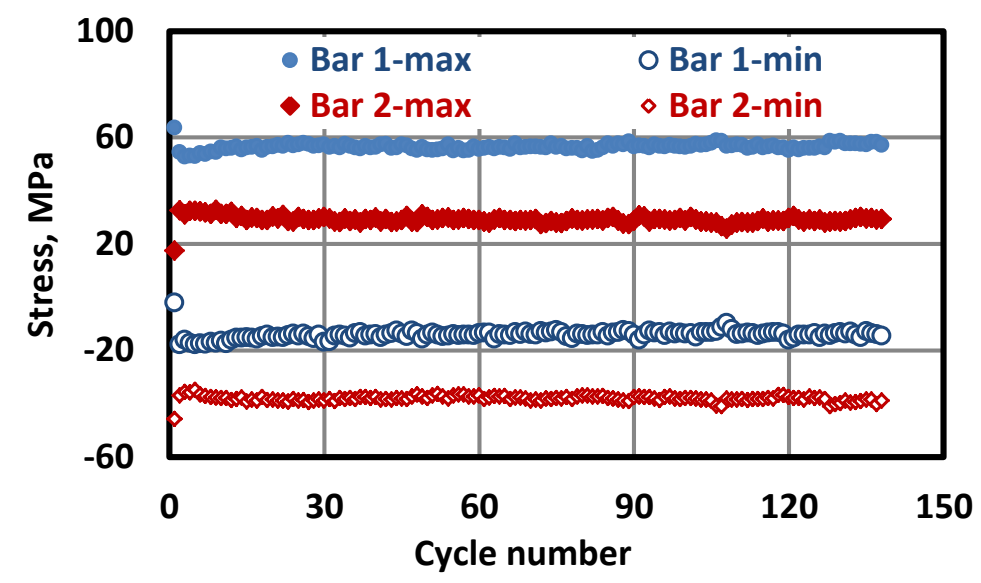

Fig. 7. Maximum and minimum stresses for test number T16

Stress vs. mechanical strain plots of the first three cycles for the two bars are shown in Fig. 8 for test number T16. The cold bar, Bar 1, showed larger mechanical strain ranges than Bar 2 under this test condition. 

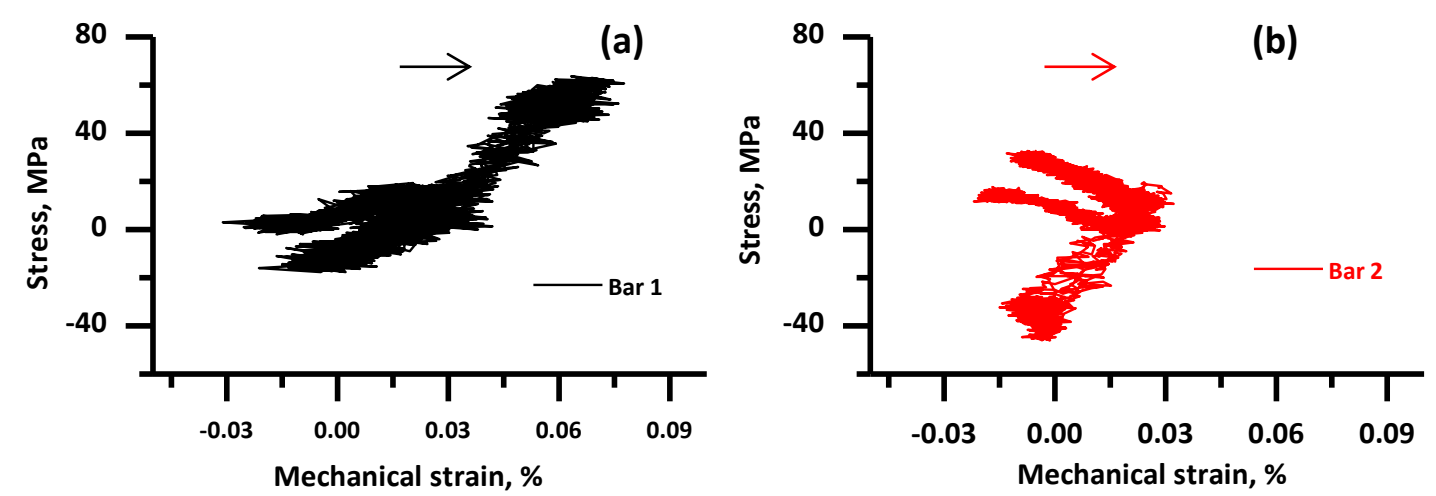

Fig. 8. Stress vs Mechanical strain plots of the first three cycles for Bar 1 (a) and Bar 2 (b) for test number T16

\subsection{EFFECT OF TIME DELAY}

The magnitude of the applied thermal stresses in the two-bar system was varied by the amount of time delay between the time Bar 1 cooled down and the onset of cooling in Bar 2. At a mean stress level of $8.1 \mathrm{MPa}$, the time delay was varied from a full time delay of $10 \mathrm{~min}$ to $5 \mathrm{~min}$ and then $3 \mathrm{~min}$. The corresponding test numbers are T17-1, T17-2 and T17-3, respectively. The maximum and minimum total strains and stresses for the two bars are presented in Fig. 9. The maximum and minimum stresses and strains were affected by the time delay. The average stress ranges for the tested cycles are summarized in Table 2. The stress ranges for both bars were reduced as the time delay was decreased and the stress ranges dropped to about $60 \%$ when the time delay was decreased from $10 \mathrm{~min}$ to $3 \mathrm{~min}$. The ratcheting rates are summarized in Table 2 and are extrapolated for a $200 \mathrm{hr}$ testing period to be $-9.0 \%,-1.2 \%$ and $0.02-0.04 \%$ for these tests with time delay of $10 \mathrm{~min}, 5 \mathrm{~min}$ and $3 \mathrm{~min}$, respectively. The relationship between the ratcheting strains and the time delays at this mean stress level of 8.1MP is shown in Fig. 10. The ratcheting rate is shown to be increasing faster as the time delay increases. Further, note that a compressive ratcheting behavior was present although the applied mean stresses were tensile for time delays of $10 \mathrm{~min}$ and $5 \mathrm{~min}$. Further, the ratcheting direction has changed from compressive to slightly tensile when the time delay was decreased from $10 \mathrm{~min}$ to $3 \mathrm{~min}$ at this mean stress level of $8.1 \mathrm{MPa}$; therefore, all time delays between zero min and those slightly less than $5 \mathrm{~min}$ will generate a state that the ratcheting in the two bars satisfies the $1 \%$ strain limits design rules. 


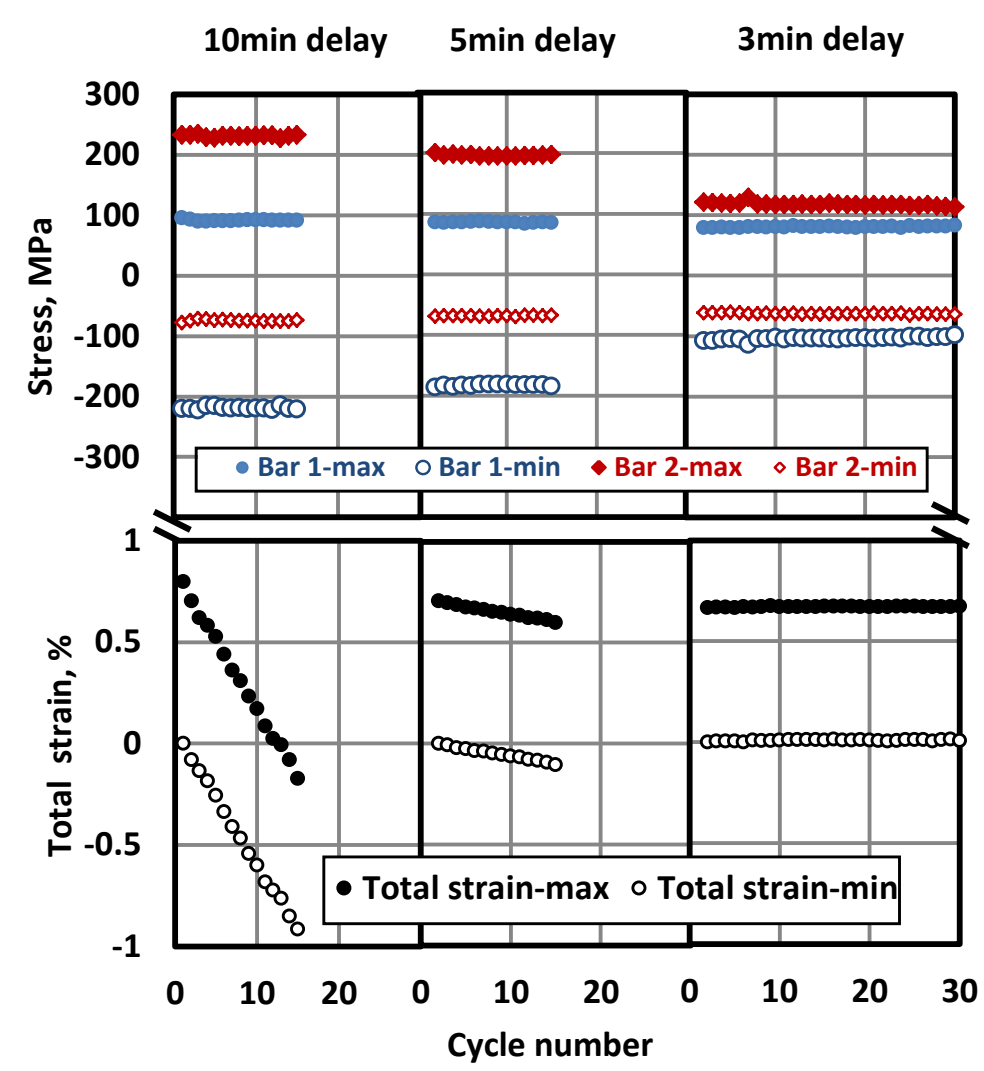

Fig. 9. Effect of time delay on the maximum and minimum total strains and stresses at a mean stress of 8.1MPa

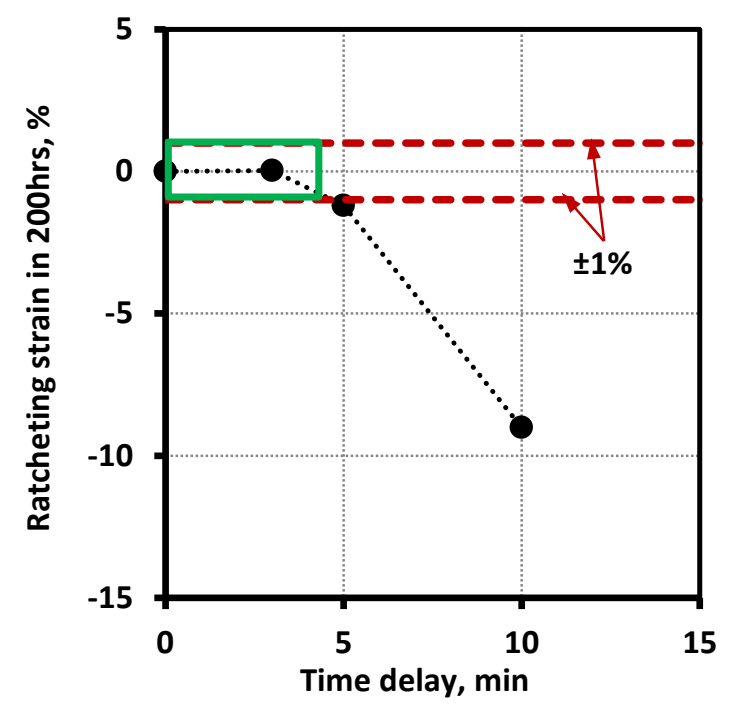

Fig. 10. Effect of time delay on the ratcheting strains at a mean stress of 8.1MPa 
Stress vs. mechanical strain hysteresis loops of the first three cycles for both bars are compared in Fig. 11 for these three tests. At the mean stress level of 8.1MPa, both the stress ranges and the mechanical strain ranges per cycle decreased for both bars when the time delay was decreased. When the time delays were 10min and 5mins, the mechanical strain ranges of the hot bar, Bar 2 are much larger than those of Bar 1. However, when the time delay was decreased to $3 \mathrm{~min}$, the strain ranges per cycle of Bar 2 became less than those of Bar 1. Therefore, the time delay has more significant effect on the mechanical strain ranges per cycle for the hot bar than those of the cold bar.

(a)
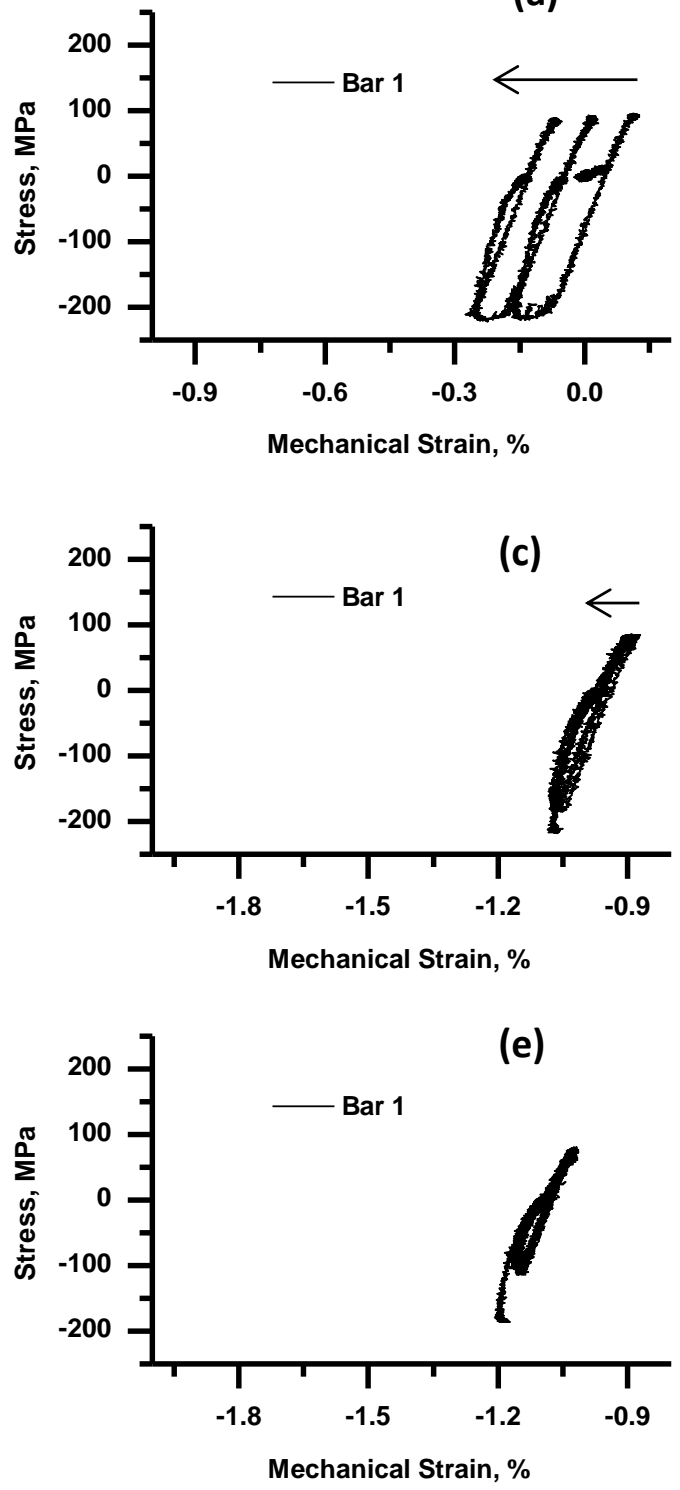

(b)
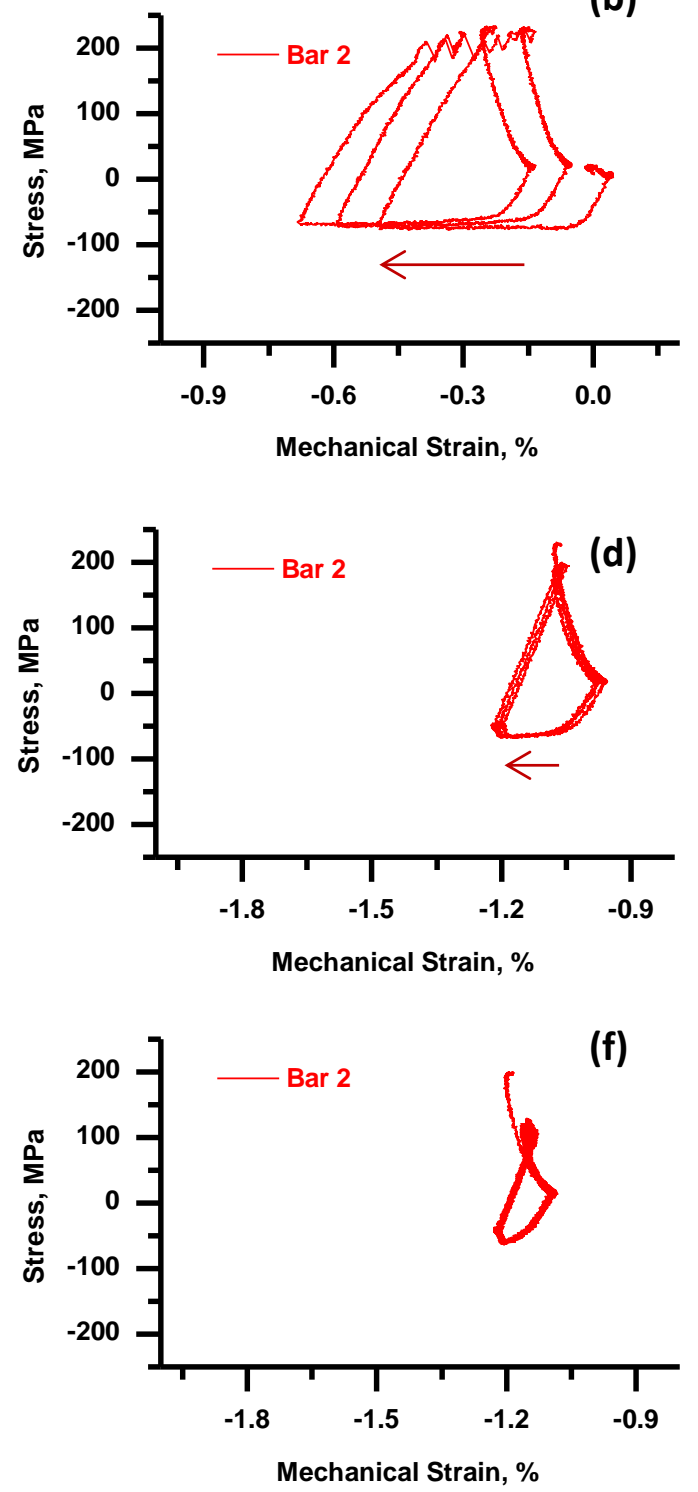

Fig. 11 Stress vs. mechanical strain plots for Bar 1 and Bar 2 for test numbers T17-1 (a, b), T17-2 (c, d) and T17-3 (e, f) 


\subsection{EFFECT OF MEAN STRESS}

The effect of applied mean stress level on the two-bar thermal ratcheting behavior of Alloy 617 was evaluated at a full time delay of $10 \mathrm{~min}$. The tested mean stresses were $4.2 \mathrm{MPa}, 7.4 \mathrm{MPa}, 15.5 \mathrm{MPa}$, $19.5 \mathrm{MPa}$ and $23.0 \mathrm{MPa}$, corresponding to test numbers T17-7, T17-1, T18-5, T18-6 and T18-7, respectively. The maximum and minimum total strains and stresses for the two bars are summarized in Fig. 12. The stress ranges for these tests are summarized in Table 2 and the changes in the stress ranges for the same bar were found to be less than $8 \mathrm{MPa}$ when the applied mean stress increased from 4.2MPa to 23.0MPa. The increase in the mean stress level was reflected by the increase in both the maximum and minimum stresses of the two bars.

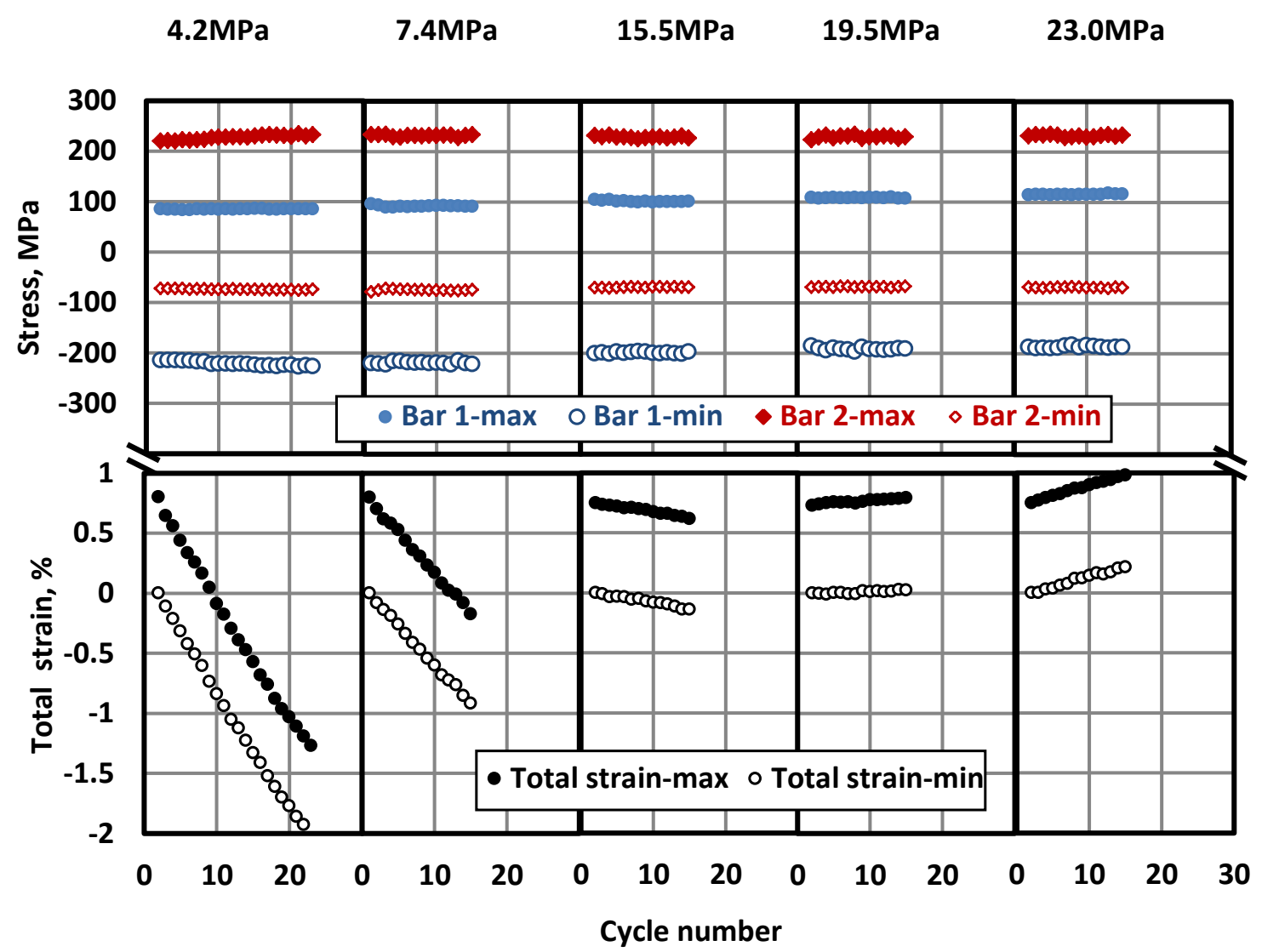

Fig. 12. Effect of applied mean stresses on the maximum and minimum total strains and stresses at time delay of $10 \mathrm{~min}$

In contrast, the changes in the ratcheting strains were large, and the values at $200 \mathrm{hr}$ were extrapolated to be $-12.5 \%,-9.0 \%,-1.3 \%, 0.3-0.6 \%$ and $2.5 \%$ for the five mean stress levels when it was increased from $4.2 \mathrm{MPa}$ to $23.0 \mathrm{MPa}$. The increase in the mean stress toward the tensile direction caused the ratcheting direction to switch from compression to tensile. The relationship between the ratcheting strains and the applied mean stresses is shown in Fig. 13. Based on the results, it can be concluded that there was a narrow range of applied mean stresses for which this high applied thermal loading results in strain accumulation of less than $\pm 1 \%$ strain limits, and the applied mean stress level should be more than 15.5MPa but less than $23.0 \mathrm{MPa}$, i.e., the range for the applied mean stress with $10 \mathrm{~min}$ time delay to cause 
less than $1 \%$ ratcheting strain in the two-bar system is less than $7.5 \mathrm{MPa}$.

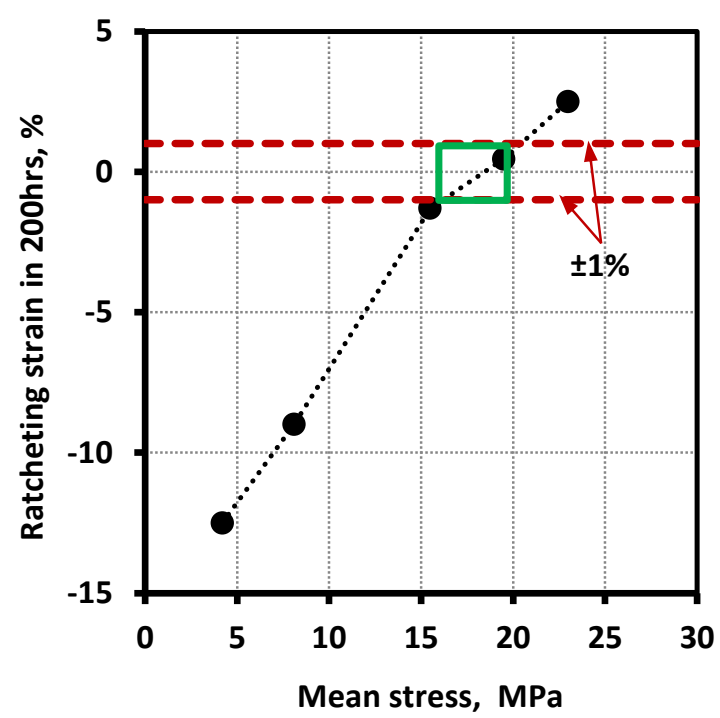

Fig. 13. Effect of applied mean stresses on the ratcheting strains at time delay of $10 \mathrm{~min}$

Stress vs. mechanical strain hysteresis loops of the first three cycles for both bars are compared in Fig. 14 for test number T17-7, T18-5 and T18-7, respectively. The shape of the hysteresis loops for Bar 1 or Bar 2 are similar except for the difference in the amount of ratcheting strains. For all three tests, the pre-existing test condition only affected the first cycle. The mechanical strain ranges for the hot bar, Bar 2, are much larger than the cold bar, Bar 1. It is also shown that Bar 2 reached its yield point at the tensile side and caused serrated yielding. 

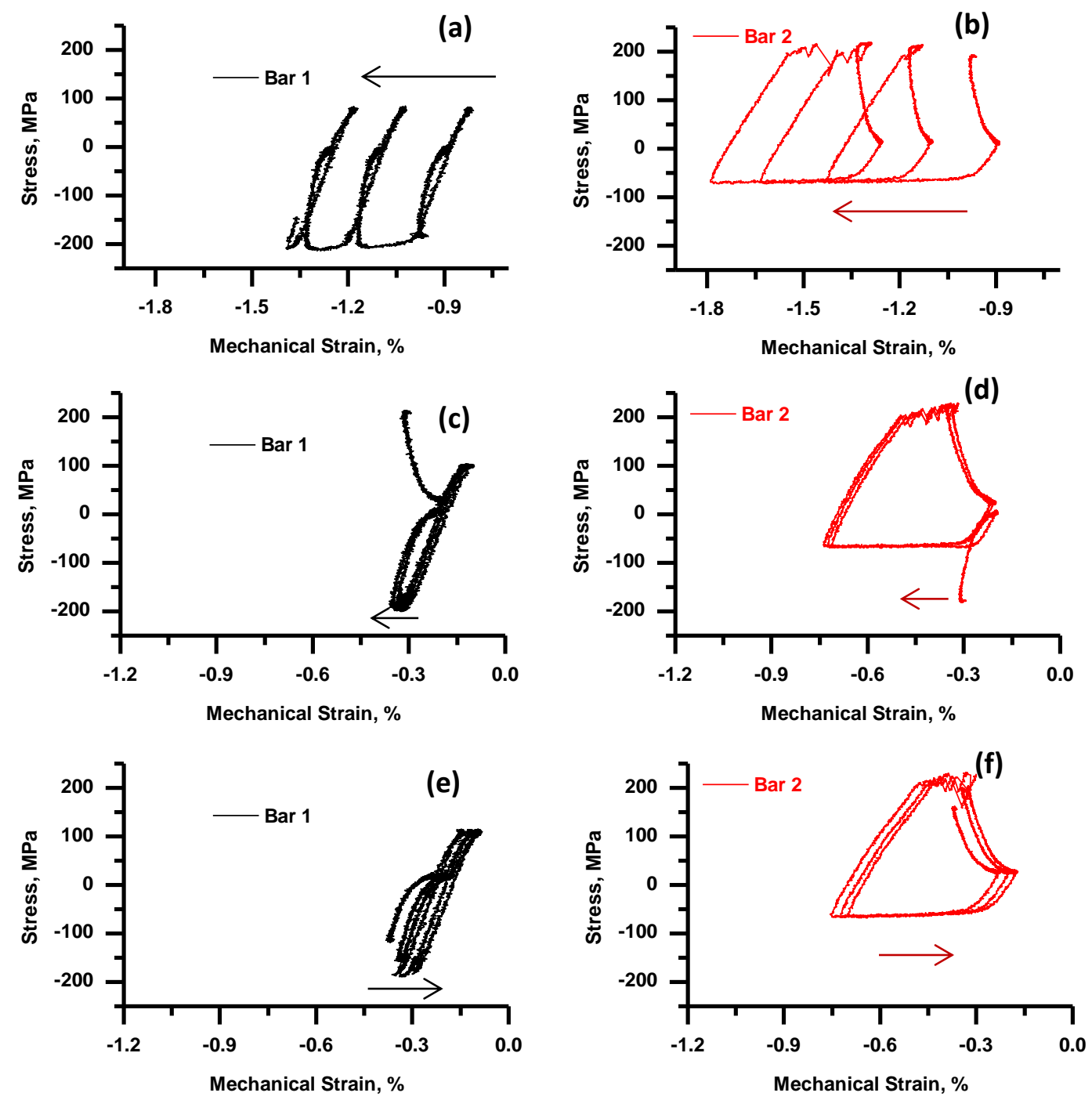

Fig. 14. Stress vs. mechanical strain plots for Bar 1 and Bar 2 for test numbers T17-7 (a, b), T18-5 (c, d) and T19-7(e, f)

\subsection{DELAYED HEATING AND COOLING}

A two-bar thermal ratcheting test with delayed heating was performed on Alloy 617 with test number T18-8 (corresponding to the temperature profile of Fig. 4B) and it is compared to test number T17-7 which was tested with delayed cooling (corresponding to the temperature profile of Fig. 4A) for the same temperature range. The time delays were both $10 \mathrm{~min}$ and the applied mean stresses were both $4.2 \mathrm{MPa}$. The heating and cooling rates were $30^{\circ} \mathrm{C} / \mathrm{min}$ for both tests. The cold bar was identified as Bar 1 for both tests. The maximum and minimum stresses and strains are compared in Fig. 15 and the stress ranges and the ratcheting rates of both testes are summarized in Table 2. There are significant differences in the test results for these two tests. First, the stress ranges of the two-bar testing with delayed heating were about $33 \mathrm{MPa}$ less than the ones with delayed cooling. Second, the maximum and the minimum stresses for the cold bar, i.e., Bar 1, were higher for the test with delayed heating, but lower for Bar 2. And third, the ratcheting rate was much faster for the test with delayed cooling and would have accumulated $-12.5 \%$ 
strain in $200 \mathrm{hrs}$, whereas, the test with delayed heating would have accumulated $-2.2 \%$ strain.

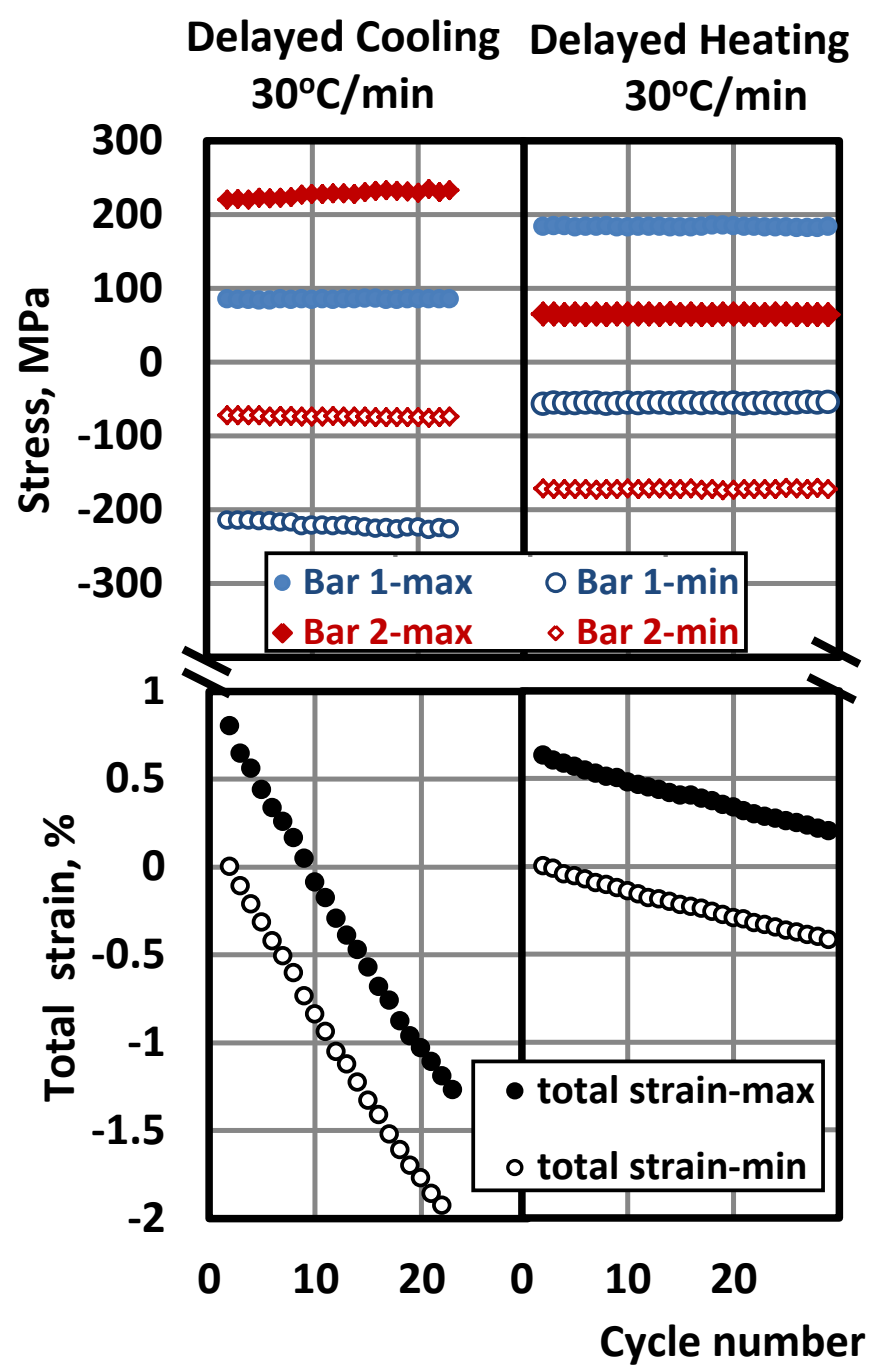

Fig. 15. Comparison of effect of delayed cooling and delayed heating

The temperature difference in the two bars is the same for these two tests. However, the temperatures where the two bars responded to the same amount of temperature difference were not the same, and hence the difference in the measured stress ranges. The compressive ratcheting strain is mainly generated by the compressive inelastic deformation of the hot bar during the delayed heating or cooling process. For the testing with delayed cooling, the hot bar (i.e. Bar 2) was at $950^{\circ} \mathrm{C}$ when Bar 1 was cooled down. However, with delayed heating, the hot bar (Bar 2) was heating up from $650^{\circ} \mathrm{C}$ to $950^{\circ} \mathrm{C}$ for the test. The effective compressive inelastic deformation in the delayed heating process is therefore less than that with delayed heating due to the fact that Alloy 617 is more resistant to inelastic deformation at lower temperatures

Stress vs. mechanical strain hysteresis loops of the first three cycles for both bars are compared in Fig. 16 for test number T17-7 and T18-8. The shape of the hysteresis loops for Bar 1 or Bar 2 are 
significantly different. For both tests, the mechanical strain ranges for the hot bar, Bar 2, are consistently much larger than for the cold bar, Bar 1. No yielding behavior was observed when a delayed heating thermal profile was applied to the two-bar system, whereas, the test with delayed cooling, T17-7 showed serrated yielding at the tensile side for Bar 2 .
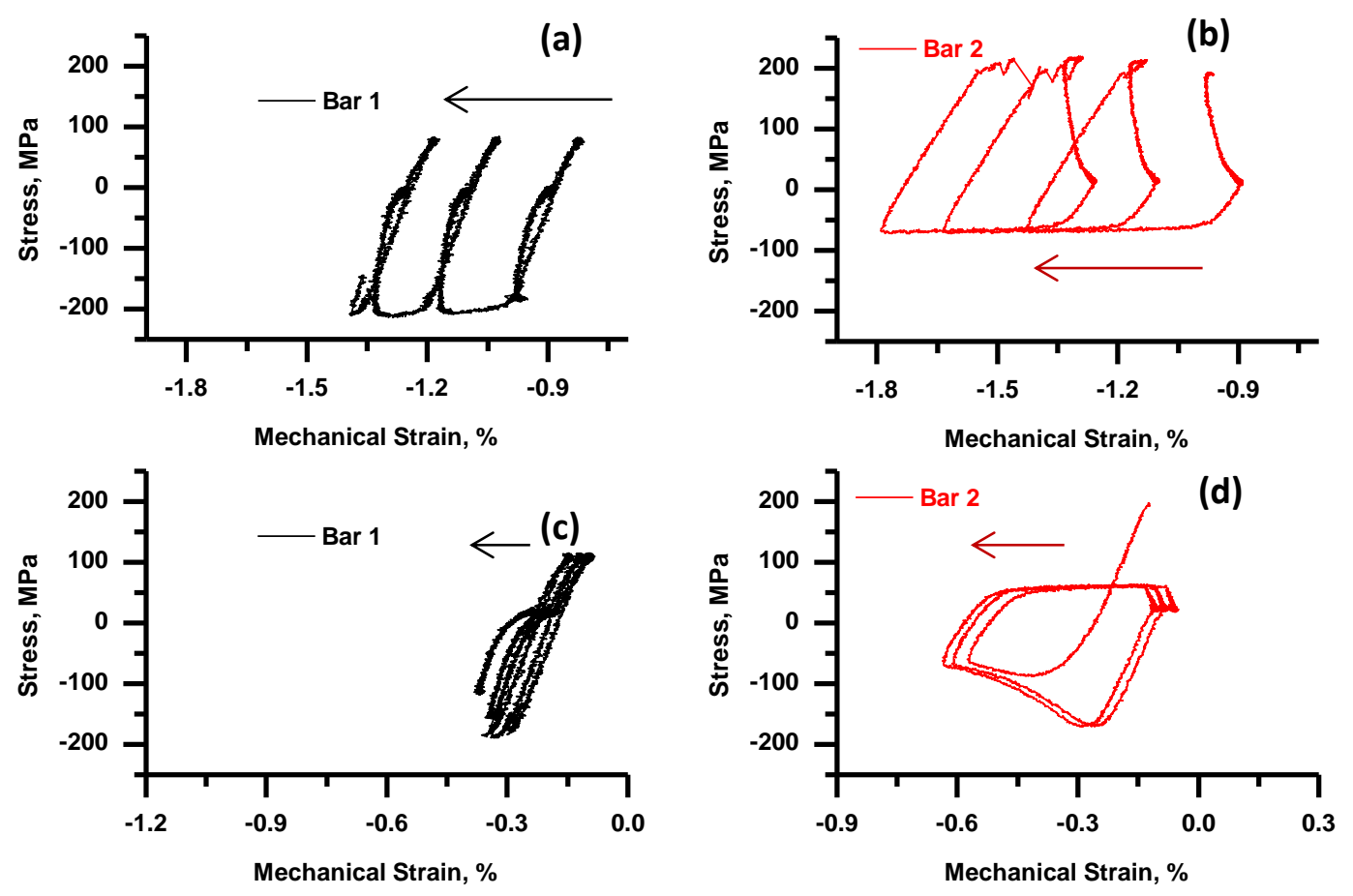

Fig. 16. Stress vs. mechanical strain plots for Bar 1 and Bar 2 for test numbers T17-7 (a, b) and T18$8(\mathbf{c}, \mathbf{d})$

\subsection{EFFECT OF HEATING AND COOLING RATES}

Tests T18-9 and T17-7 were performed to assess the heating and cooling effects on Alloy 617 when tested under the two bars in parallel condition. The differences in the testing parameters for these two tests are listed in Table 2. The heating and cooling rates were $5^{\circ} \mathrm{C} / \mathrm{min}$ for $\mathrm{T} 18-9$ and $30^{\circ} \mathrm{C} / \mathrm{min}$ for T177. The mean applied stresses were slightly different for the two tests, and the values were $4.6 \mathrm{MPa}$ for T18-9 and 4.2MPa for T17-7. The total time for one cycle was $4 \mathrm{hr}$ for T18-9 and 1.5hr for T17-7. The maximum and minimum stresses and strains are compared in Fig. 17 and the stress ranges and the ratcheting rates of both tests are summarized in Table 2. The maximum stresses in Bar 2 and the minimum stress in Bar 1 were at the same level for the two tests, but the stress range was $20 \mathrm{MPa}$ larger for T17-7 which was tested at faster heating and cooling rates of $30^{\circ} \mathrm{C} / \mathrm{min}$. The stress response is consistent with the effect of strain rates on the mechanical behavior of Alloy 617 as this material is strain rate sensitive at $950^{\circ} \mathrm{C}$. The two bars ratchet at $-0.08 \%$ per cycle for $\mathrm{T} 18-9$, and at a slightly higher ratcheting rate of $-0.09 \%$ per cycle for T17-7. Note that when it is evaluated for the same testing time period, the accumulated time at higher temperature for the hot bar (Bar 2) is longer during the delayed cooling segment for the slow heating and cooling tests. Although the compressive ratcheting strain is mainly due to the compressive inelastic deformation of the hot bar (Bar 2), the faster heater and cooling rates have caused more severe ratcheting strains per cycle. 
As discussed earlier, a main motivation for the development of new design rules was the observation that at very high temperatures in Alloy 617 it is not possible to decouple plasticity and creep. Further, recent studies on Alloy 617 also indicate that the material creeps very fast at $950^{\circ} \mathrm{C}$. For example, it was shown that the stresses in Alloy 617 relaxed $~ 70 \%$ in less than $10 \mathrm{sec}$ during the hold period when being tested at $950^{\circ} \mathrm{C}$ with a standard strain-controlled creep-fatigue configuration by Carrol et al.(2010). In this study, the time durations of the hot bar (Bar 2) for both fast and slow test conditions were long enough to allow the specimen go through most of the stress relaxation. Therefore, even if theoretically feasible, the creep and plastic deformation cannot be separated and estimated through these testing results.

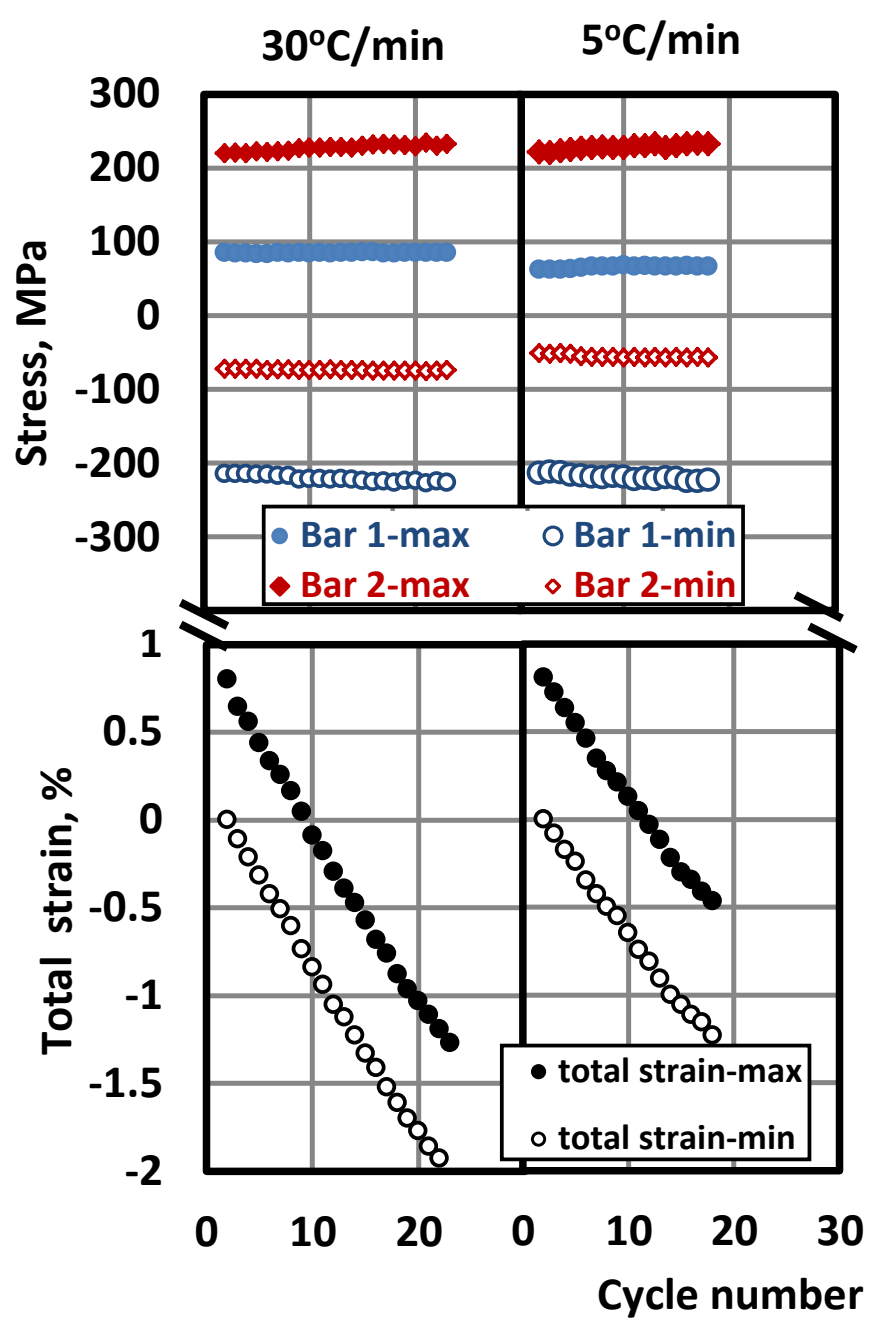

Fig. 17. Effect of heating and cooling rates

Stress vs. mechanical strain hysteresis loops of the first three cycles for both bars are compared in Fig. 18 for test number T17-7 and T18-9. The shape of the hysteresis loops for Bar 1 or Bar 2 are similar but not identical. For both tests, the mechanical strain ranges for the hot bar, Bar 2, are shown to be much larger than the cold bar, Bar 1. 

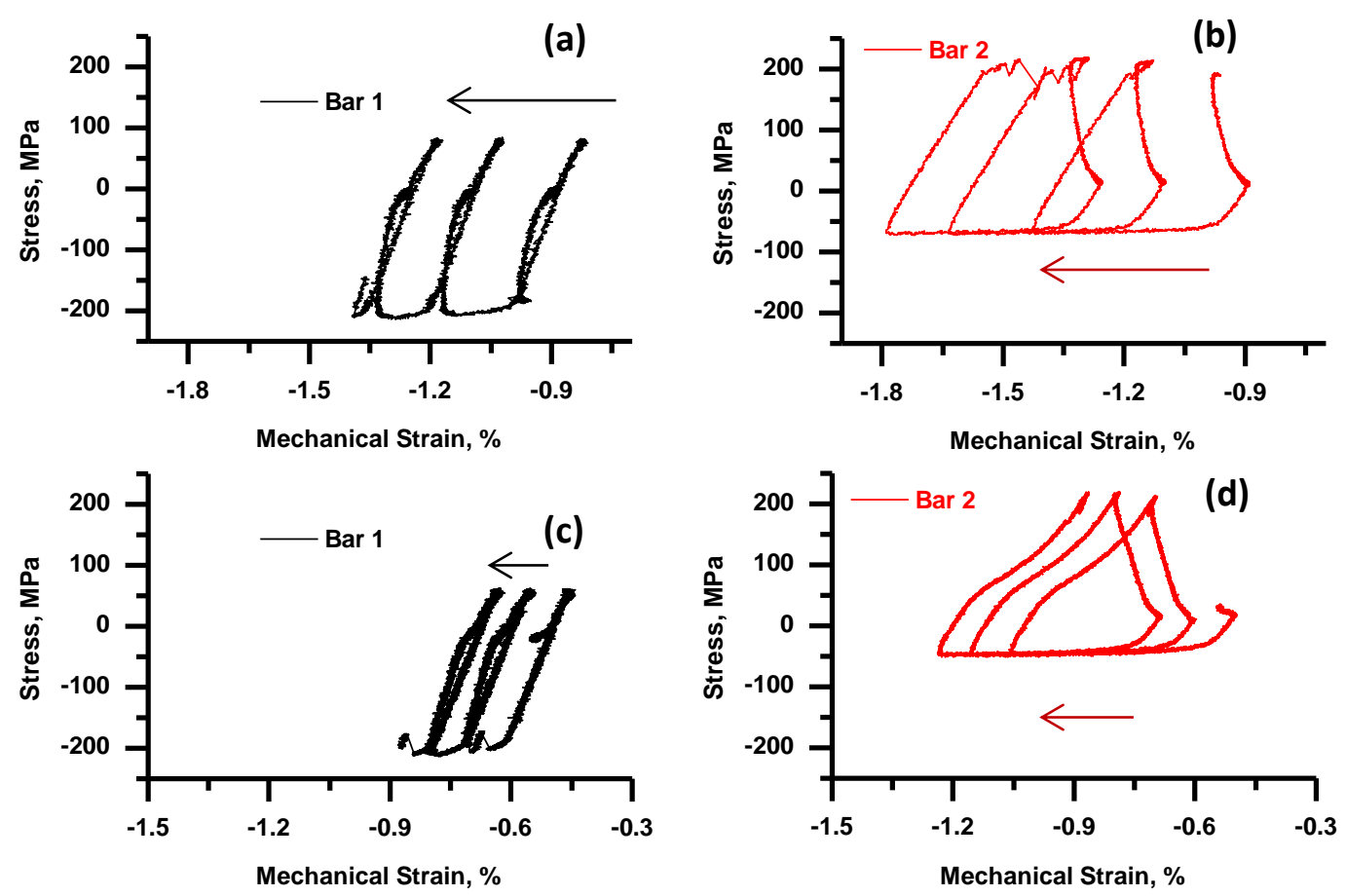

Fig. 18. Stress vs. mechanical strain plots for Bar 1 and Bar 2 for test numbers T17-7 (a, b) and T18-8 (c, d)

\subsection{FURTHER DISCUSSIONS}

As shown in the experimental results, there are significant differences in the mechanical behavior for the two bars when tested under two-bar in parallel conditions. This indicates that the pressurized component that the two-bar system represents will experience a gradient in the mechanical loading during operation. This gradient could cause differences in inelastic strain accumulations during long term operations. Therefore, in order to understand the structural integrity for long term applications, there is a need for testing Alloy 617 under several representative two-bar in parallel conditions for long-term or till failure occurs.

Further, the distinct features of the stress-strain curves for the two-bar in parallel tests could be used to calibrate the constitutive models for Alloy 617 at these temperature ranges. The unique relationship between the two-bar testing parameters and the strain limits provides critical information for verification of the EPP methodology.

In addition, this report has coved the test results for the two-bar testing condition with temperature range of $650^{\circ} \mathrm{C}$ to $950^{\circ} \mathrm{C}$, however, the applicability of the EPP methodology for strain limits to a lower temperature is also of great interest. Test data will be generated under two-bar in parallel testing condition at lower temperatures to support this verification process. 


\section{SUMMARY}

Two-bar thermal ratcheting experiments were performed on Alloy 617 under two bars in parallel condition using two coupled servo-hydraulic machines. Tests performed at heating and cooling rates of $30^{\circ} \mathrm{C} / \mathrm{min}$ are comparable to a strain rate of $10^{-5} / \mathrm{sec}$ and those at $5^{\circ} \mathrm{C} / \mathrm{min}$ are about $10^{-6} / \mathrm{sec}$. The magnitude of the applied temperature difference between the two bars was varied by the amount of time delay between the time Bar 1 cooled down and the onset of the cooling in Bar 2.

Two-bar thermal ratcheting test results with combinations of applied mean stresses, transient temperature difference and heating and cooling rates were recorded. At high mean stresses in tension the direction of ratcheting was in-phase with the load, e.g., tensile strain ratcheting under high tensile loading; however, at lower loads, strain ratcheting in compression was observed under net tensile mean stresses. The strain accumulation was found to be proportional to the applied thermal load. However, there was a narrow range of applied load in which the high applied thermal loading did not result in a significant strain accumulation. These results are being used to assess the applicability of the proposed design rules for strain limits in the creep regime, particularly at very high temperatures for Alloy 617.

Future testing plans for Alloy 617 two-bar in parallel testing program include long-term two-bar testing and testing under conditions that are representative for verification of EPP methodology. 


\section{REFERENCES}

Bree, J., (1967), "Elastic -Plastic Behavior of Thin Tubes Subjected to Internal Pressure and Intermittent High-Heat Fluxes with Applications to Fast Nuclear Reactor Fuel Elements," Journal of Strain Analysis Vol. 2, No. 3.

Conway, J. B., et al., (1975), "Thermal Ratcheting Studies of Type 304 Stainless Steel-An Evaluation of a New Test Method," Structural Materials for Service at Elevated Temperature in Nuclear Power Generation, A.O. Schaefer, ed., MPC-1, p. 247, American Society for Mechanical Engineers, New York.

Corum and Blass, (1991), Rules for Design of Alloy 617 Nuclear Components to Very High Temperatures, ASME PVP Vol. 215, p. 147, American Society of Mechanical Engineers, New York, NY.

Carter, P., Jetter, R., Sham, T.-L., (2012a), "Application of Elastic-Perfectly Plastic Cyclic Analysis to Assessment of Creep Strain," PVP 2012 - 28082, American Society of Mechanical Engineers, New York, NY.

Carter, P., Jetter, R., Sham, T.-L., (2012b), "Application of Shakedown Analysis to Evaluation of CreepFatigue Limits,” PVP 2012-28083, American Society of Mechanical Engineers, New York, NY.

Carroll L.J., Cabet, C., Wright, R. N., (2010), "The Role of Environment on High Temperature CreepFatigue Behavior of Alloy 617," Proceedings of the ASME 2010 Pressure Vessels and Piping Division Conference, Bellevue, Washington, USA, July 2012, PVP2010-26126, American Society of Mechanical Engineers, New York, NY.

Carroll L.J., Cabet, C., Carroll, M. C. and Wright, R. N., (2013), "The development of microstructural damage during high temperature creep-fatigue of a nickel alloy," Int. J. Fatigue, 47, 115, DOI: 10.1016/j.ijfatigue.2012.07.016

O’Donnell, W., and Porowski, J., (1974), "Upper Bounds for Accumulated Strains Due to Creep Ratcheting," Journal of Pressure Vessel Technology, Vol. 96, p. 126.

Sartory, W., (1989) "Effect of Peak Thermal Strain on Simplified Analysis Procedures," PVP-Vol. 163, American Society of Mechanical Engineers, New York, NY.

Swindeman, R., Robinson, D., Williams, B. and Thomas, D., (1982) "Two-Bar Thermal Ratcheting Experiments on 21/4Cr-1Mo steel, " ORNL/TM-8001, Oak Ridge National Laboratory, Oak Ridge, TN.

Wang, Y., Sham, T.-L, and Jetter, R .I., (2014), "Two-Bar Thermal Ratcheting for Alloy 617 Part I: Scoping Tests," Journal of Pressure Vessel Technology, ASME, accepted.

Wang, Y., Sham, T.-L, and Jetter, R .I., (2013), "Progress report on the development of test procedure for the two-bar thermal ratcheting experiment for Alloy 617," ORNL/TM-2013/318, Oak Ridge National Laboratory, Oak Ridge, TN. 
ORNL/TM-2014/294

\section{ELECTRONIC DISTRIBUTION}

Name

Corwin, W.

Hemrick, J.G.

Hill, R.N.

Jetter, R.I.

Lara-Curzio, E.

Nanstad, R.K.

Robinson, B.

Sham, T.-L.

Wang, Y.

Wright, R.N.

ORNL Office of Technical

Information

and Classification

\section{Email}

DOE

ORNL

ANL

Global Engineering and

Technology LLC

ORNL

ORNL

DOE

ORNL

ORNL

INL

\author{
william.corwin@nuclear.energy.gov \\ hemrickjg@ornl.gov \\ bobhill@anl.gov \\ bjetter@sbcglobal.net \\ laracurzioe@ornl.gov \\ nanstadrk@ornl.gov \\ brian.robinson@nuclear.energy.gov \\ shamt@ornl.gov \\ wangy3@ornl.gov \\ richard.wright@inl.gov
}

